\title{
Constitutive activation of MEK1 in chondrocytes causes Stat1-independent achondroplasia-like dwarfism and rescues the Fgfr3-deficient mouse phenotype
}

\author{
Shunichi Murakami, ${ }^{1,3}$ Gener Balmes, ${ }^{1}$ Sandra McKinney, ${ }^{1}$ Zhaoping Zhang, ${ }^{1}$ David Givol, ${ }^{2}$ \\ and Benoit de Crombrugghe ${ }^{1,3}$ \\ ${ }^{1}$ Department of Molecular Genetics, The University of Texas, M.D. Anderson Cancer Center, Houston, Texas 77030, USA; \\ ${ }^{2}$ Weizmann Institute of Science, Rehovot, Israel, 76100
}

\begin{abstract}
We generated transgenic mice that express a constitutively active mutant of MEK1 in chondrocytes. These mice showed a dwarf phenotype similar to achondroplasia, the most common human dwarfism, caused by activating mutations in FGFR3. These mice displayed incomplete hypertrophy of chondrocytes in the growth plates and a general delay in endochondral ossification, whereas chondrocyte proliferation was unaffected. Immunohistochemical analysis of the cranial base in transgenic embryos showed reduced staining for collagen type $X$ and persistent expression of Sox9 in chondrocytes. These observations indicate that the MAPK pathway inhibits hypertrophic differentiation of chondrocytes and negatively regulates bone growth without inhibiting chondrocyte proliferation. Expression of a constitutively active mutant of MEK1 in chondrocytes of Fgfr3-deficient mice inhibited skeletal overgrowth, strongly suggesting that regulation of bone growth by FGFR3 is mediated at least in part by the MAPK pathway. Although loss of Stat1 restored the reduced chondrocyte proliferation in mice expressing an achondroplasia mutant of Fgfr3, it did not rescue the reduced hypertrophic zone, the delay in formation of secondary ossification centers, and the achondroplasia-like phenotype. These observations suggest a model in which Fgfr3 signaling inhibits bone growth by inhibiting chondrocyte differentiation through the MAPK pathway and by inhibiting chondrocyte proliferation through Stat1.
\end{abstract}

[Keywords: MEK1; MAPK; FGFR3; Stat1; chondrocyte differentiation; achondroplasia]

Received October 6, 2003; revised version accepted December 19, 2003.

Endochondral ossification, in which bone replaces preexisting cartilage, is the predominant form of bone formation. During this process, bones grow longer at the epiphyseal growth plates, where chondrocytes progress through a series of differentiation stages. Chondrocytes in the reserve zone first proliferate, then exit the cell cycle and undergo hypertrophic differentiation. Longitudinal growth is achieved by proliferation of chondrocytes, deposition of matrix, and increase in volume that takes place in hypertrophic chondrocytes. The cartilaginous matrix of hypertrophic chondrocytes is subsequently invaded by blood vessels together with cartilageresorbing chondroclasts/osteoclasts and differentiating bone-forming osteoblasts. Hypertrophic chondrocytes are removed from the growth plate at the chondro-osse-

${ }^{3}$ Corresponding authors.

E-MAIL smurakam@mdanderson.org; FAX (713) 794-4295.

E-MAIL bdecromb@mdanderson.org; FAX (713) 794-4295.

Article and publication are at http://www.genesdev.org/cgi/doi/10.1101/ gad.1179104. ous junction through a process that involves apoptotic cell death. Various signaling molecules have been shown to regulate and coordinate this complex process of endochondral ossification. Among these, fibroblast growth factor (FGF) signaling has been shown to play critical roles in the regulation of bone growth. FGF receptor 3 (FGFR3) is expressed in proliferating and prehypertrophic chondrocytes in the epiphyseal growth plates $(\mathrm{Pe}-$ ters et al. 1993; Delezoide et al. 1998; Naski et al. 1998; Ohbayashi et al. 2002). Activating mutations in FGFR3 cause the most common forms of human dwarfism, namely, achondroplasia, hypochondroplasia, and thanatophoric dysplasias (Rousseau et al. 1994, 1995; Shiang et al. 1994; Bellus et al. 1995; Tavormina et al. 1995). Expression of activating FGFR3 mutants in mice reproduces the dwarf phenotype of these skeletal diseases (Naski et al. 1998; Li et al. 1999; Wang et al. 1999; Iwata et al. 2000, 2001; Segev et al. 2000; Chen et al. 2001). In contrast, lack of Fgfr3 in mice causes skeletal overgrowth, indicating that Fgfr3 signaling inhibits endochondral bone growth (Colvin et al. 1996; Deng et al. 
1996). Similarly, transgenic mice that overexpress FGFs show dwarfism (Coffin et al. 1995; Garofalo et al. 1999), whereas mice homozygous for a targeted disruption of Fgf18 exhibit a growth-plate phenotype similar to that of Fgfr3-null mice (Liu et al. 2002; Ohbayashi et al. 2002). These observations indicate that FGFs and FGFR3 signaling play major roles in the regulation of bone growth.

Despite recent advances in understanding the roles of FGFs and FGF receptors in skeletal development, little is known about the intracellular signals that mediate the actions of FGFs. FGFs have been shown to activate multiple signal transduction pathways; these include Stat1, Stat3, Stat5, ERK1, ERK2, p38 mitogen-activated protein kinases (MAPKs), phospholipase C- $\gamma$, protein kinase C, Src, phosphatidylinositol 3-kinase, and Akt (Su et al. 1997; Legeai-Mallet et al. 1998; Sahni et al. 1999; Murakami et al. 2000; Debiais et al. 2001; Ronchetti et al. 2001; Kong et al. 2002; Shimoaka et al. 2002). Among these, Stat1 has been proposed to be a mediator of the activity of FGFR3 in chondrocytes. Stat 1 has been localized in the nucleus of chondrocytes of human thanatophoric dysplasia and its mouse models, hence indicating its activation ( $\mathrm{Su}$ et al. 1997; Legeai-Mallet et al. 1998; Li et al. 1999). In addition, up-regulation of $\mathrm{p} 21^{\mathrm{WAF} 1 / \mathrm{CIP} 1}$, a cell cycle inhibitor that functions downstream of Stat1, has been observed in chondrocytes of human thanatophoric dysplasia, accounting at least partially for the inhibition of chondrocyte proliferation. Furthermore, loss of Stat1 restores the reduced chondrocyte proliferation and normal bone length in transgenic mice that overexpress FGF2 under the control of a phosphoglycerate kinase promoter (Sahni et al. 2001). These observations suggest that Stat 1 activation is involved in the dwarf phenotype of achondroplasia and thanatophoric dysplasias. However, the transient and limited expansion of the proliferating zone in the growth plate in Stat1-null mice is considerably milder than that of Fgfr3-null mice, strongly suggesting the existence of additional pathways that mediate Fgfr3 signaling in skeletal development. It remains unknown whether loss of Stat 1 is sufficient to rescue the dwarf phenotype caused by activating mutations in Fgfr3.

We have previously shown that FGFs up-regulate expression of Sox 9 in chondrocytes in culture (Murakami et al. 2000). Sox9 is an HMG-box-containing transcription factor that is essential for chondrocyte differentiation. Up-regulation of Sox 9 by FGFs is inhibited by a specific inhibitor of the MAPK pathway, strongly suggesting that Sox9 expression in chondrocytes can be regulated by the MAPK pathway. Sox 9 is expressed in all chondroprogenitor cells and chondrocytes, but its expression is completely abolished in hypertrophic chondrocytes. In mouse chimeras, Sox 9 homozygous mutant cells are excluded from chondrogenic mesenchymal condensations and cartilages and could not express chondrocyte markers such as Col2a1 (Bi et al. 1999). Recent data obtained in our laboratory also indicate that Sox9 inhibits hypertrophic differentia- tion of chondrocytes in vivo. Sox 9 heterozygous mutant mice, which mimic the phenotype of human campomelic dysplasia, show enlarged zones of hypertrophic chondrocytes and premature mineralization in the growth plates (Bi et al. 2001). In addition, conditional inactivation of Sox 9 using the Cre-loxP system after mesenchymal condensation results in premature hypertrophy of chondrocytes (Akiyama et al. 2002). Given the essential role of Sox9 at multiple steps of chondrocyte differentiation, we hypothesized that the MAPK pathway plays an important role in the regulation of chondrocyte differentiation.

To determine the role of the MAPK pathway in chondrocyte differentiation, we generated transgenic mice that express a constitutively active mutant of mitogen-activated protein kinase/ERK kinase 1 (MEK1; S218/222E, $\Delta 32-51)$ in chondrocytes and studied the resulting phenotypes. MEK1 is activated by various growth factors including FGFs. MEK1 in turn phosphorylates and activates ERK1 and ERK2 MAPKs. This mutant MEK1 contains serine-to-glutamic acid substitutions of the two phosphoacceptors at amino acids 218 and 222 in combination with an internal deletion from amino acid 32 to amino acid 51. These mutations result in high constitutive activity of MEK1, and the mutant does not need to be activated by other protein kinases (Mansour et al. 1994; Coso et al. 1995; $\mathrm{Lu}$ and Zheng 1998). We show here that expression of MEK1 (S218/222E, $\Delta 32-51)$ in chondrocytes inhibited hypertrophic differentiation of chondrocytes and delayed endochondral ossification without affecting chondrocyte proliferation. These mice showed an achondroplasialike phenotype, characterized by hypoplasia of the cranial base and shortening of the axial and appendicular skeletons. Expression of the constitutively active MEK1 (S218/222E, $\Delta 32-51)$ in chondrocytes of Fgfr3-deficient mice inhibited skeletal overgrowth, suggesting that the reduced activity of the MAPK pathway plays an important role in the skeletal overgrowth in Fgfr3-null mice. Furthermore, expression of MEK1 (S218/222E, $\Delta 32-51)$ in chondrocytes of Stat1-null mice caused an achondroplasia-like phenotype, indicating that the growth-inhibitory effect of the MAPK pathway is independent of Stat1. Multiple genes were regulated by FGFs in an MAPK-dependent manner in Stat1-null chondrocytes in culture. Consistent with these observations, human achondroplasia mutation in Fgfr3 caused an achondroplasia-like phenotype in Stat1-null mice. Although loss of Stat1 rescued the reduced chondrocyte proliferation, it only corrected bone length to a very minor extent. Together, these observations indicate that the MAPK pathway is a negative regulator of bone growth and strongly suggest that the MAPK pathway plays an important role in the development of the dwarf phenotype in human achondroplasia and thanatophoric dysplasias. These observations suggest a model in which Fgfr3 signaling inhibits bone growth by inhibiting chondrocyte differentiation through the MAPK pathway and by inhibiting chondrocyte proliferation through Stat1. 
Murakami et al.

\section{Results}

Phosphorylation of MEK1 and ERK1/2 by various growth factors

We first examined phosphorylation, hence activation, of MEK1 and ERK1 and ERK2 by growth factors in chondrocytes. Primary chondrocytes isolated from wild-type mice were serum-starved for $24 \mathrm{~h}$ and subsequently treated with saturating doses of FGF18, EGF, PDGF-BB, TGF- $\beta$, and IGF-I. All of those factors caused phosphorylation of MEK1 and its substrates ERK1 and ERK2 to variable degrees with different time frames (Fig. 1A,B). FGF18, EGF, and PDGF-BB induced the most robust phosphorylation, and FGF18 caused the most prolonged phosphorylation. This robust and prolonged phosphorylation of MEK1, ERK1, and ERK2 correlated with up-

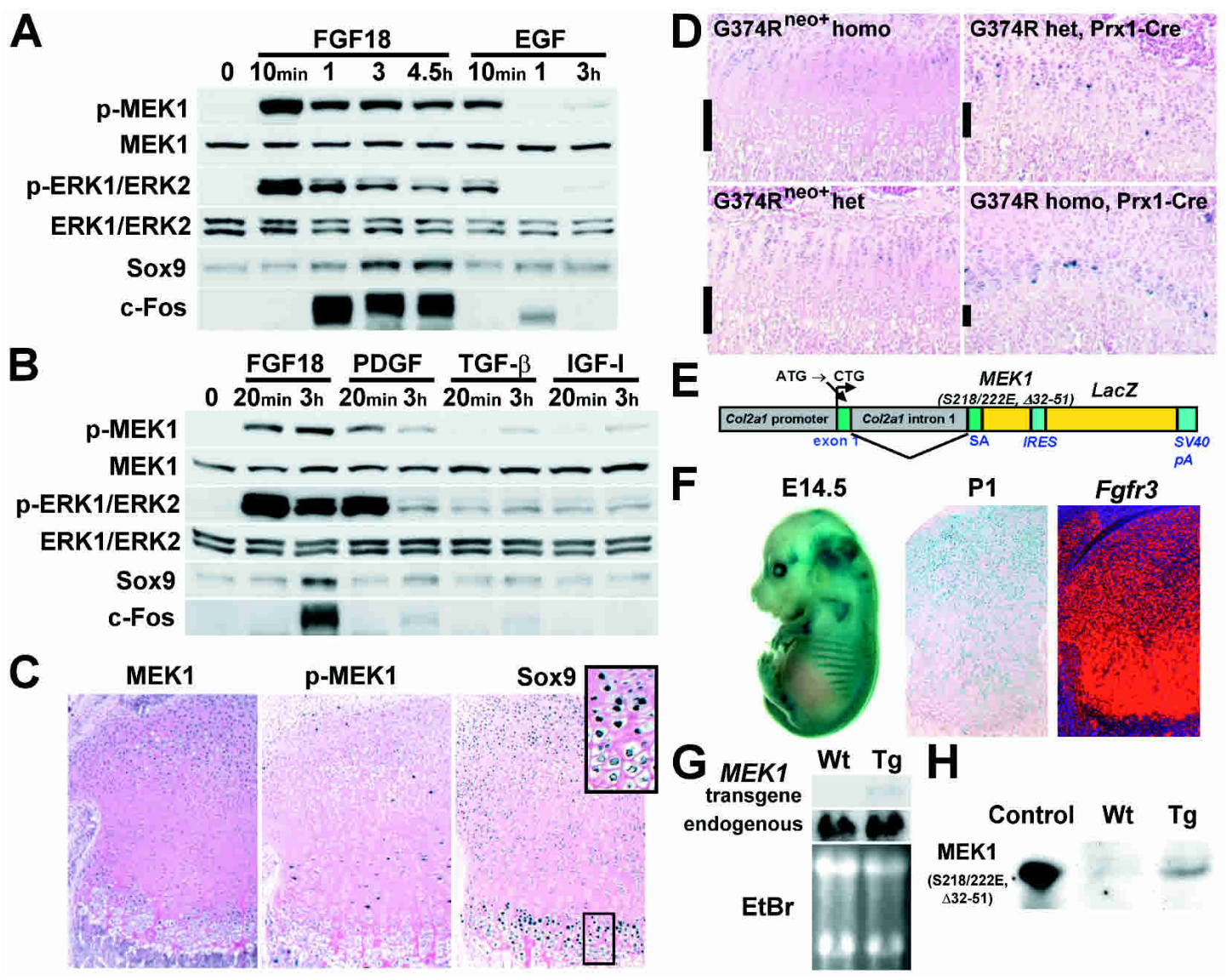

Figure 1. $(A, B)$ Prolonged phosphorylation of ERK1, ERK2, and MEK1 after FGF18 treatment in primary chondrocytes. Chondrocytes were prepared from the ribs of newborn mice. Confluent culture was serum-starved for $24 \mathrm{~h}$ and treated with $20 \mathrm{ng} / \mathrm{mL}$ FGF18, 20 ng/mL EGF, $100 \mathrm{ng} / \mathrm{mL}$ PDGF-BB, $20 \mathrm{ng} / \mathrm{mL}$ TGF- $\beta$, and $100 \mathrm{ng} / \mathrm{mL}$ IGF-I. Cells were harvested at indicated periods of time after treatment. Total and phosphorylated ERK1, ERK2, and MEK1 proteins, Sox9, and c-Fos were detected by Western blot analysis. (C) Immunostaining of MEK1 (left) and its phosphorylated form (middle) and Sox9 (right) in the proximal tibia of a wild-type mouse at P7. Sox9 staining in hypertrophic chondrocytes is magnified for subcellular localization. (D) Immunostaining of phosphorylated MEK1 in the proximal tibial growth plates in Fgfr3 mutant littermates at P21. Increased staining for phosphorylated MEK1 was observed in the growth plate chondrocytes of heterozygous and homozygous mice expressing an achondroplasia mutant of Fgfr3 (G374R) compared with heterozygous and homozygous mice carrying a hypomorphic allele of Fgfr3 (G374R neo ${ }^{+}$. Similar results were observed in the femur and radius. Fgfr3 mutant mice homozygous for the hypomorphic G374R neo ${ }^{+}$allele show skeletal overgrowth similar to Fgfr3-null mice, whereas heterozygous mice show normal bone growth. The Prx1-Cre transgenic mouse line was used to delete the neomycin cassette that interfered with normal splicing of Fgfr3, causing an achondroplasia mutant Fgfr3 G374R to be expressed. Bars indicate the position of the zone of hypertrophic chondrocytes. (E) Schematic representation of the construct that drives expression of a constitutively active mutant of MEK1 in chondrocytes. The original initiation codon of Col2a1 was mutated to CTG to facilitate translation from downstream cDNA. $(F)$ X-gal staining of an E14.5 embryo showing cartilage-specific expression of the transgene (left). X-gal staining of the distal femoral growth plate of a transgenic mouse at P1 (middle) and in situ hybridization of Fgfr3 of the corresponding area in a wild-type littermate (right). $(G)$ Northern blot analysis using a probe for MEK1. A transcript of $\sim 7 \mathrm{~kb}$ was detected in the limb and rib cartilages of transgenic mice. The MEK1 transgene expression was $5 \%$ of the endogenous MEK1 expression. The lower panels show ethidium bromide staining of RNA as a loading control. $(H)$ Western blot analysis using an anti-Flag M5 antibody. The Flag-tagged mutant MEK1 protein is expressed in chondrocytes isolated from the ribs. A cell lysate of C3H10T1/2 cells stably transfected with the Flag-tagged MEK1 was run as a control. (Wt) Wild type; $(\mathrm{Tg})$ transgenic. 
regulation of Sox9 and c-Fos, suggesting that the magnitude and duration of MAPK activation may be important in MAPK-mediated gene regulation by FGFs.

\section{Expression of endogenous MEK1 in the growth plates}

We further examined the expression of MEK1 and its phosphorylation, Sox9, and Fgfr3 in the developing long bones by immunohistochemistry and in situ hybridization. MEK1 was expressed in virtually all chondrocytes throughout the growth plate, showing more intense staining in chondrocytes of the prehypertrophic zone and chondrocytes surrounding the developing secondary ossification center (Fig. 1C). Immunohistochemistry using a phospho-specific antibody showed the presence of phosphorylated MEK1 in chondrocytes with increased staining in some of the chondrocytes in the proliferating zone. Sox 9 protein was expressed in the nucleus of all chondrocytes except hypertrophic chondrocytes. In hypertrophic chondrocytes, where Sox 9 transcript was absent by in situ hybridization, Sox 9 protein was absent from the nucleus, but some immunoreactivity was detected in the cytoplasm. Interestingly, Sox9 protein expression increased in chondrocytes of the prehypertrophic zone and in chondrocytes surrounding the developing secondary ossification center. Fgfr3 was expressed at low levels in periarticular chondrocytes and at higher levels in chondrocytes of the proliferating and prehypertrophic zones (Fig. 1E). These results indicate that Fgfr3, $M E K 1$, and Sox 9 are coexpressed in the growth-plate chondrocytes.

We then examined phosphorylation of MEK1 in chondrocytes of Fgfr3-mutant mice (Wang et al. 1999). In this line of Fgfr3-mutant mice, insertion of the neomycin cassette into intron 4 of $F g$ rr 3 interfered with the normal splicing of Fgfr3 mRNA, making the mutant allele hypomorphic. When the neomycin cassette is removed by the Cre-loxP system, normal splicing takes place, and Fgfr3 G374R that corresponds to human achondroplasia mutant G380R is expressed. We used Prx1-Cre transgenic mice that express Cre recombinase in the developing limb bud to delete the neomycin cassette in the limbs of heterozygous and homozygous Fgfr3-mutant mice (Logan et al. 2002). Expression of Fgfr3 G374R caused a dosage-dependent shortening of long bones of the limbs (data not shown), whereas heterozygous mice without the Prx1-Cre transgene showed normal bone growth, and homozygous mice without the Prx1-Cre transgene showed Fgfr3-deficient phenotype characterized by skeletal overgrowth. At postnatal day $(\mathrm{P}) 8$, we did not observe an obvious difference in phosphorylation of MEK1 in mice expressing Fgfr3 G374R /data not shown). At P21, we observed a more intense staining for phosphorylated MEK1 in the growth-plate chondrocytes of mice expressing Fgfr3 G374R compared with heterozygous and homozygous Fgfr3-mutant mice without the Prx1-Cre transgene (Fig. 1D). These results strongly suggest that phosphorylation of MEK1 in the growth-plate chondrocytes is caused at least in part by signals originating from Fgfr3.

\section{Generation of transgenic mice}

To induce the expression of a constitutively active mutant of MEK1 (S218/222E, $\Delta 32-51$ ) in chondrocytes, the $M E K 1 \mathrm{cDNA}$ was cloned into a vector containing $3 \mathrm{~kb}$ of the Col2a1 promoter and $3.02 \mathrm{~kb}$ of intron 1 sequences (Fig. 1E). Three out of eight established transgenic lines (lines A, B, and C) showed intense cartilage-specific X-gal staining (Fig. 1F). At P1, X-gal staining was observed in growth-plate chondrocytes, indicating that the expression domains of the transgene overlap with those of Fgfr3.

Expression of the transgene in lines A and B was further confirmed by Northern and Western blot analyses. Northern blot analyses using probes for MEK1 and LacZ each showed the same 7-kb transcript in the limb and rib cartilages (Fig. 1G; data not shown). The transgene MEK1 expression was $\sim 5 \%$ of the endogenous MEK1. The Flagtagged MEK1 protein (S218/222E, $\Delta 32-51)$ was detected in primary chondrocytes by Western blot analysis using anti-Flag M5 antibody (Fig. 1H).

When heterozygous mice were mated to each other, 59 of 73 offspring $(81 \%)$ were positive for the transgene, close to the expected rate of $75 \%$, in line B, whereas only 35 of 63 offspring (56\%) were positive for the transgene in line $\mathrm{A}$; hence, suggestive of embryonic lethality in homozygous mice. Interestingly, when a transgenic male in line B was crossed with a wild-type female, all male offspring were wild type and all female offspring harbored the transgene, thus indicating the X-linked inheritance of the transgene in line B.

Expression of a constitutively active mutant of MEK1 in chondrocytes causes achondroplasia-like dwarfism

Lines A, B, and C all exhibited a similar dwarf phenotype (Fig. 2A). Skeletal preparations of newborn mice showed shortened axial and appendicular skeletons, midfacial hypoplasia, and a dome-shaped cranium reminiscent of achondroplasia (Fig. 2B). Midfacial hypoplasia and associated cranial deformities are characteristics of human dwarfism syndromes caused by activating mutations of FGFR3. These cranial features are generally considered to be due to disproportionate growth between the cranial base formed by endochondral ossification and calvaria formed by intramembranous ossification. Examination of the head from the caudal view revealed remarkable hypoplasia of the sphenoid, basisphenoid, and basioccipital bones along with anteriorly displaced foramen magnum, similar to that seen in mouse models of achondroplasia that harbor activating mutations in Fgfr3 (Fig. 2C). Mineralization of vertebral bodies was delayed, and lamina of the cervical vertebrae were occasionally fused with neighboring vertebrae (Fig. 2D,E). Skeletal preparations of 6 -wk-old mice showed proportional shortening of long bones and limb girdles (Fig. 2F). We also measured the length of long bones in 4-wk-old mice of line A. The average distance between the proximal and distal growth plates was $10 \%-13 \%$ shorter in females and $5 \%-$ $7 \%$ shorter in males than in wild-type littermates (Table 1). 
Murakami et al.

Figure 2. (A) Transgenic and wild-type littermates in line A mice at $3 \mathrm{wk}$ of age. Transgenic mice expressing a constitutively active MEK1(S218/222E, $\Delta 32-51)$ in chondrocytes showed an achondroplasia-like dwarf phenotype. (Tg) Transgenic; (Wt) wild-type. (B) Skeletal preparation of newborn line $\mathrm{C}$ mice after alizarin red and alcian blue staining. Transgenic mice expressing a constitutively active mutant of MEK1 in chondrocytes showed an achondroplasia-like phenotype characterized by shortened axial and appendicular skeletons, midfacial hypoplasia, and a rounded cranium. $(C)$ Caudal view of the head showing remarkable hypoplasia of the sphenoid (sp), basisphenoid (bs), and basioccipital (bo) bones, along with an anteriorly displaced foramen magnum. Anterior $(D)$ and lateral $(E)$ views of the cervical spine, showing a delay in ossification of vertebral bodies and fusions of lamina (arrow) with neighboring vertebrae in transgenic mice expressing MEK1 (S218/ $222 \mathrm{E}, \Delta 32-51)$ in chondrocytes. $(F)$ Long bones and limb girdles of transgenic and wildtype littermates in line A mice at $6 \mathrm{wk}$ of age. Transgenic mice expressing MEK1(S218/ $222 \mathrm{E}, \Delta 32-51)$ in chondrocytes showed proportional shortening of long bones and limb girdles.

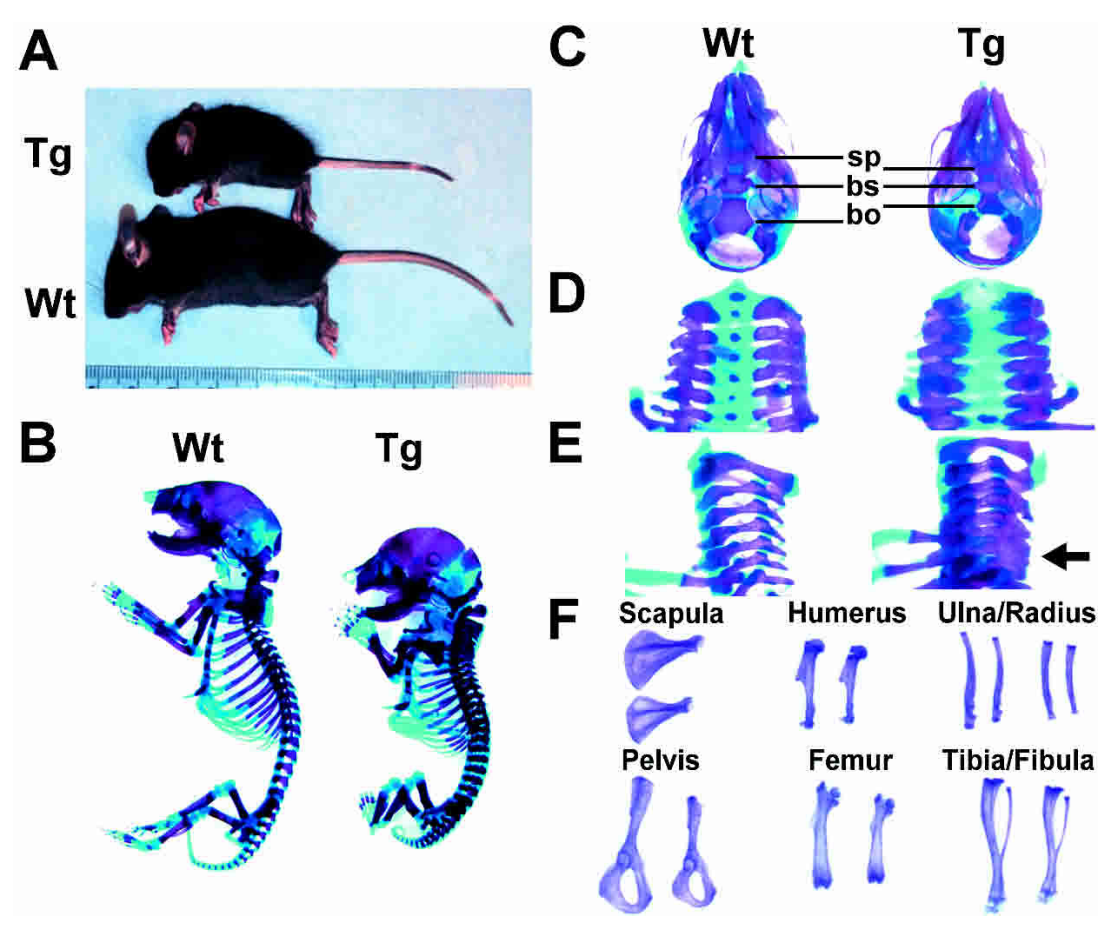

Growth-plate phenotype of mice expressing a constitutively active mutant of MEK1

The histology of epiphyseal growth plates was examined at various time points between embryonic day 14.5 (E14.5) and postnatal day 24 (P24) in lines A and B. From E15.5 onward, the growth plates consistently showed narrower zones of hypertrophic chondrocytes. Hypertrophic chondrocytes in transgenic mice remained relatively small throughout the growth plate (Fig. 3A,B). Reduction of the hypertrophic zone was further confirmed by immunostaining for type $\mathrm{X}$ collagen, a specific marker of hypertrophic chondrocytes (Fig. 3F,G).

For comparison, we examined mice harboring a human achondroplasia mutation in Fgfr3 (Wang et al. 1999). We used Zp3-Cre transgenic mice that express Cre recombinase in oocytes to delete the neomycin cassette in heterozygous Fgfr3-mutant mice (Lewandoski et al. 1997) and Prx1-Cre transgenic mice that express Cre recombinase in the developing limb bud to delete the neomycin cassette in the limbs of homozygous Fgfr3mutant mice. Expression of Fgfr3 G374R caused a dosage-dependent reduction in the hypertrophic zone and the cell size of hypertrophic chondrocytes, indicating the similarity between mice that express MEK1/S218/222E, $\Delta 32-51$ ) and mice that express Fgfr3 G374R (Fig. $3 \mathrm{C}, \mathrm{D}, \mathrm{E})$. The width of the hypertrophic zone and the size of hypertrophic chondrocytes of transgenic mice were comparable to those of homozygous Fgfr3 G374R mutant mice with the Prx1-Cre transgene. The average cell height of the last two layers of hypertrophic chondrocytes was $75.7 \% \pm 18.6 \%$ in transgenic mice that express MEK1(S218/222E, $\Delta 32-51)$ and $73.2 \% \pm 12.8 \%$ in homozygous Fgfr3 G374R mutant mice with the Prx1-Cre transgene relative to wild-type controls.

We also examined the formation of secondary ossification centers in the tibia and femur at $\mathrm{P} 7$ in transgenic mice that express MEK1(S218/222E, $\Delta 32-51)$ in chondrocytes (Fig. 3H,I). At this stage, chondrocytes in the

Table 1. Distance between the proximal and distal growth plates at 4 wk of age

\begin{tabular}{llcccc}
\hline & & Humerus & Ulna & Femur & Tibia \\
\hline Male & WT $(n=13)$ & $8.38 \pm 0.21$ & $10.83 \pm 0.31$ & $10.27 \pm 0.32$ & $12.86 \pm 0.35$ \\
& $\operatorname{Tg}(n=11)$ & $7.98 \pm 0.51^{\mathrm{a}}$ & $10.23 \pm 0.52^{\mathrm{b}}$ & $9.52 \pm 0.75^{\mathrm{b}}$ & $12.02 \pm 0.69^{\mathrm{b}}$ \\
Female & $\mathrm{WT}(n=5)$ & $8.34 \pm 0.22$ & $10.78 \pm 0.23$ & $10.20 \pm 0.28$ & $12.86 \pm 0.27$ \\
& $\operatorname{Tg}(n=8)$ & $7.52 \pm 0.62^{\mathrm{b}}$ & $9.75 \pm 0.73^{\mathrm{b}}$ & $8.90 \pm 0.92^{\mathrm{b}}$ & $11.39 \pm 0.88^{\mathrm{b}}$ \\
\hline
\end{tabular}

Long bones of transgenic mice were shorter than in wild-type mice, and this difference was statistically significant. (WT) Wild type; ( $\mathrm{Tg}$ ) transgenic.

Mann-Whitney $\mathrm{U}$ test; ${ }^{\mathrm{a}} p<0.05 .{ }^{\mathrm{b}} p<0.01$. Length in millimeters $( \pm \mathrm{SD})$. 


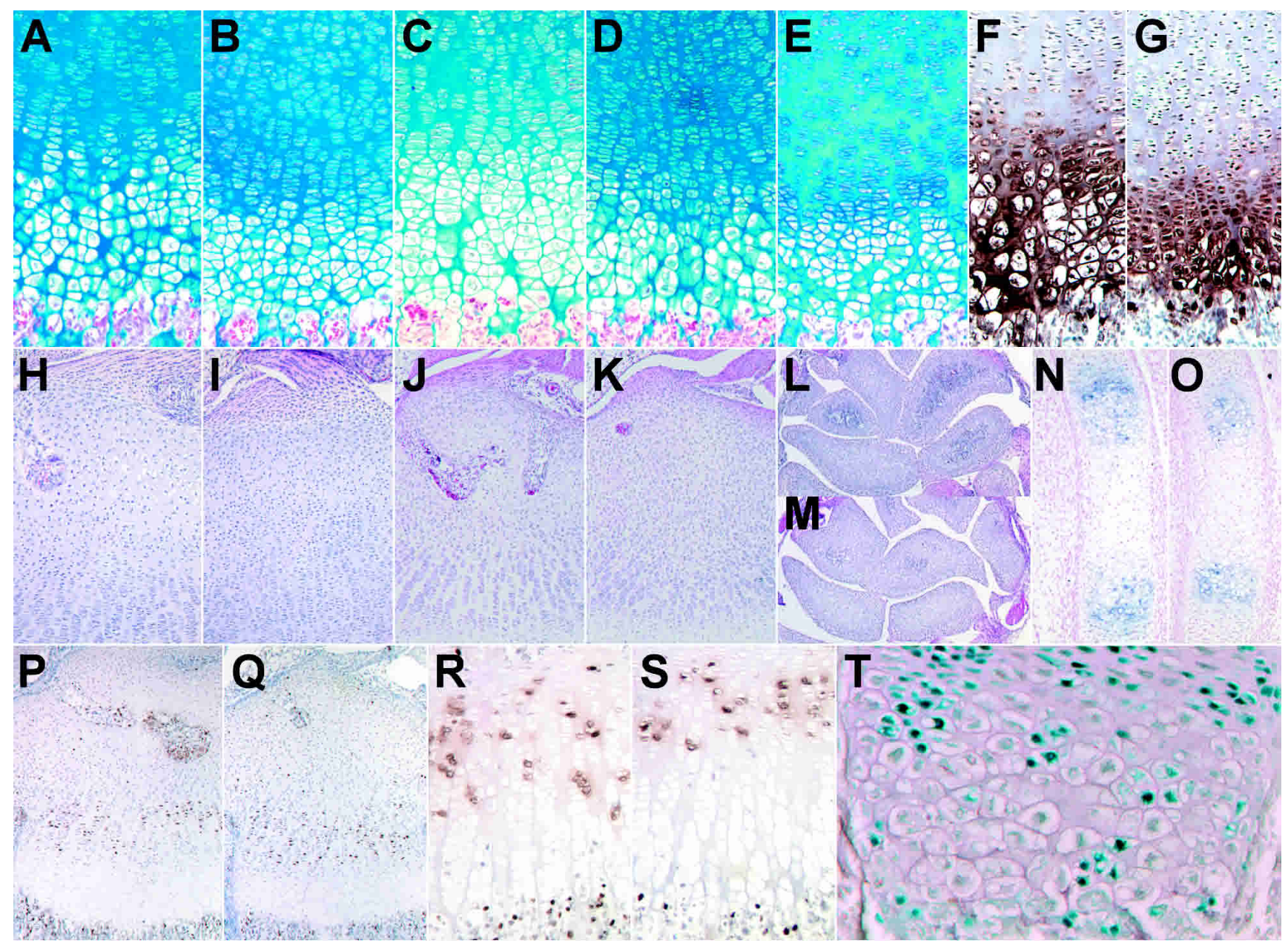

Figure 3. Alcian blue staining of proximal tibial growth plates of wild-type $(A)$ and transgenic $(B)$ littermates in line A at P4. Transgenic mice expressing MEK1(S218/222E, $\Delta 32-51)$ in chondrocytes showed smaller than normal hypertrophic chondrocytes in the growth plate. $(C-E)$ Alcian blue staining of proximal tibial growth plates of wild-type $(C)$, heterozygous $(D)$, and homozygous $(E)$ Fgfr3 mutant mice that express Fgfr3 G374R at P4. Mice expressing Fgfr3 G374R show dosage-dependent reduction in the size of hypertrophic chondrocytes and width of the hypertrophic zone. $(F, G)$ Type X collagen immunostaining of proximal tibial growth plates of wild-type $(F)$ and transgenic $(G)$ male littermates in line B at P7, showing a reduced zone of hypertrophic chondrocytes in transgenic mice. $(H-K)$ Hematoxylin and eosin staining of the proximal tibia at the level of cruciate ligament insertion. Transgenic mice expressing MEK1(S218/222E, $\Delta 32-51)$ in chondrocytes $(I)$ showed a delay in the formation of secondary ossification centers compared with their wild-type littermates $(H)$ at P7. Similar delay is observed in heterozygous Fgfr3 mutant mice that express Fgfr3 G374R at P8; $(J)$ wild-type; $(K)$ Fgfr3 G374R. $(L, M)$ Carpal bones of wild-type $(L)$ and transgenic $(M)$ female littermates in line A at P9. Ossification of carpal bones was delayed in transgenic mice. $(N, O)$ Indian hedgehog $(I h h)$ expression in fibulae of E15.5 wild-type $(N)$ and doubletransgenic $(O)$ embryos that harbor the transgenes of both lines A and B. Ihh expression was unaltered in transgenic mice expressing MEK1(S218/222E, $\Delta 32-51)$ in chondrocytes. $(P, Q)$ There was no difference in BrdU incorporation in chondrocytes of the proximal tibial growth plates between wild-type $(P)$ and transgenic $(Q)$ littermates in line A at P8. $(R, S)$ Localization of BrdU-labeled cells 26 h after administration of BrdU at P13. Because cells in the hypertrophic zone do not proliferate and do not incorporate BrdU, the presence of BrdU-labeled cells in the hypertrophic zone would indicate that these cells have undergone hypertrophic differentiation after incorporating BrdU in the proliferating zone. Within $26 \mathrm{~h}$ after administration of BrdU, BrdU-labeled cells advanced to the upper $1 / 3$ of the hypertrophic zone in wild-type mice $(R)$, while BrdU-positive cells stayed in the prehypertrophic region in transgenic mice that express MEK1(S218/222E, $\Delta 32-51)$ in chondrocytes $(S)$. (T) X-gal staining of the proximal femoral growth plate of a heterozygous female E15.5 embryo in line B, showing a mosaic pattern of transgene expression consistent with inactivation of one of the X-chromosomes in females. Chondrocytes that stained positive for X-gal were smaller than neighboring chondrocytes that did not stain with X-gal, indicating that the MAPK pathway inhibited chondrocyte hypertrophy in a cell-autonomous manner.

middle of epiphysis became hypertrophic and vascular invasion was initiated in wild-type mice. In transgenic mice, on the other hand, chondrocytes in the epiphysis remained small and vascular invasion was not initiated, indicating that formation of secondary ossification centers was delayed. In addition, endochondral ossification of carpal bones was delayed in these transgenic mice (Fig. $3 \mathrm{~L}, \mathrm{M})$. Similar delay in the formation of secondary ossi- 
fication centers and ossification of carpal bones was observed in mice that express Fgfr3 G374R (Fig. 3J,K; data not shown). Together, these results indicate that expression of MEK1(S218/222E, $\Delta 32-51)$ in chondrocytes delayed hypertrophic differentiation and endochondral ossification similarly to the effects of achondroplasia mutation in Fgfr3. We examined the expression of some of the regulators and markers of hypertrophic differentiation in these transgenic mice (i.e., Indian hedgehog [Ihh], Runx2, Sox9, and osteopontin). We did not observe any differences in the expression levels of Ihh by in situ hybridization or Runx2, Sox9, and osteopontin by immunohistochemistry (Fig. 3N,O; data not shown).

In addition to hypertrophy of chondrocytes, bone growth is achieved by chondrocyte proliferation. Postnatal reduction in chondrocyte proliferation has been reported in mice that express achondroplasia or thanatophoric dysplasia mutants of Fgfr3 (Naski et al. 1998; Iwata et al. 2001). To assay chondrocyte proliferation, we examined BrdU incorporation in the proximal tibia of transgenic mice that express MEK1(S218/222E, $\Delta 32-51$ ) in chondrocytes and of heterozygous mice that express Fgfr3 G374R at various time points. Consistent with previous reports, mice that express Fgfr3 G374R showed progressive reduction in BrdU-incroporating cells from P8 onward. In contrast, transgenic mice that express MEK1(S218/222E, $\Delta 32-51)$ in chondrocytes did not show a decrease in the number of BrdU-positive cells, indicating that reduced chondrocyte proliferation is not the primary cause of dwarfism in these mice (Fig. 3P,Q; Table 2).

We also performed a pulse-chase experiment, in which localization of BrdU-labeled cells was examined $26 \mathrm{~h}$ af- ter administration of BrdU at P13. Because cells in the hypertrophic zone do not proliferate and do not incorporate BrdU, the presence of BrdU-labeled cells in the hypertrophic zone would indicate that these cells have undergone hypertrophic differentiation after incorporating BrdU in the proliferating zone. Within $26 \mathrm{~h}$ after administration of BrdU, BrdU-labeled cells advanced to the upper $1 / 3$ of the hypertrophic zone in wild-type mice, whereas BrdU-positive cells stayed in the prehypertrophic region in transgenic mice (Fig. 3R,S), indicating that hypertrophic differentiation of growth-plate chondrocytes takes place at a reduced rate in transgenic mice that express a constitutively active MEK1/S218/222E, $\Delta 32-51)$. Similar results were also observed in mice that express Fgfr3 G374R (data not shown).

Interestingly, mice that express MEK1/S218/222E, $\Delta 32-51$ ) in chondrocytes and heterozygous Fgfr3 G374R mutant mice both showed an increased cellularity in the proliferating zone as determined by the localization of BrdU-incorporating cells (Table 2). There was a statistically significant increase in cellularity at multiple time points in both animals. Because chondrocyte proliferation is increased in neither mice, this hypercellularity could be due to reduced accumulation of matrix per cell, which could be a consequence of reduced matrix production or increased matrix degradation. The reduced matrix accumulation could at least partially account for the reduced bone growth in both animals. We examined alcian blue staining, type II collagen, and MMP13 proteins by immunohistochemistry, and Col2a1 mRNA by in situ hybridization; however, we did not observe obvious differences between transgenic mice and wild-type littermates (data not shown). It is possible that changes in

Table 2. Percentage of BrdU-incorporating cells and cell density in the proliferating zone of proximal tibial growth plates in transgenic mice that express MEK1(S218/222E, D32-51) in chondrocytes and mice that express Fgfr3 G374R

\begin{tabular}{|c|c|c|c|c|c|c|c|}
\hline Age & Gender & Genotype & BrdU-positive cells (\%) & Number & Significance & Cell number $/ 0.01 \mathrm{~mm}^{2}$ & $\overline{\text { Significance }}$ \\
\hline \multirow[t]{2}{*}{ E16.5 } & & Transgenic (double) & $13.2 \pm 4.8$ & $n=6(2)$ & N.S. & $84.1 \pm 7.1$ & $p<0.05$ \\
\hline & & Wild-type & $12.0 \pm 6.0$ & $n=12(4)$ & & $74.6 \pm 9.6$ & \\
\hline \multirow[t]{2}{*}{ P8 } & Female & Transgenic (line A) & $15.4 \pm 4.2$ & $n=12(4)$ & N.S. & $48.4 \pm 7.4$ & N.S. \\
\hline & & Wild-type & $19.3 \pm 5.8$ & $n=7(2)$ & & $47.9 \pm 7.8$ & \\
\hline \multirow[t]{2}{*}{ P14 } & Male & Transgenic (line B) & $24.3 \pm 2.9$ & $n=25(5)$ & N.S. & $48.7 \pm 4.5$ & $p<0.05$ \\
\hline & & Wild-type & $25.5 \pm 5.6$ & $n=16(3)$ & & $42.0 \pm 3.0$ & \\
\hline \multirow[t]{2}{*}{$\mathrm{P} 21$} & Male & Transgenic (line A) & $22.3 \pm 4.0$ & $n=26(5)$ & N.S. & $44.2 \pm 5.9$ & $p<0.05$ \\
\hline & & Wild-type & $24.3 \pm 3.7$ & $n=15(3)$ & & $39.1 \pm 2.6$ & \\
\hline \multirow[t]{2}{*}{$\mathrm{P} 4$} & Female & Fgfr3 G374R & $12.9 \pm 4.6$ & $n=17(6)$ & N.S. & $49.2 \pm 6.4$ & $p<0.05$ \\
\hline & & Wild-type & $11.5 \pm 6.0$ & $n=12(4)$ & & $44.6 \pm 4.9$ & \\
\hline \multirow[t]{2}{*}{ P8 } & Male & Fgfr3 G374R & $8.4 \pm 2.5$ & $n=12(4)$ & $p<0.05$ & $55.7 \pm 5.8$ & $p<0.01$ \\
\hline & & Wild-type & $13.3 \pm 3.6$ & $n=6(2)$ & & $46.6 \pm 3.3$ & \\
\hline \multirow[t]{2}{*}{ P12 } & Male & Fgfr3 G374R & $5.8 \pm 2.5$ & $n=9(3)$ & $p<0.01$ & $50.9 \pm 7.4$ & $p<0.01$ \\
\hline & & Wild-type & $16.9 \pm 5.0$ & $n=6(2)$ & & $37.1 \pm 7.0$ & \\
\hline \multirow[t]{2}{*}{ P21 } & Male & Fgfr3 G374R & $2.6 \pm 2.5$ & $n=16(4)$ & $p<0.001$ & $61.3 \pm 12.9$ & $p<0.001$ \\
\hline & & Wild-type & $22.1 \pm 6.6$ & $n=16(4)$ & & $43.4 \pm 7.0$ & \\
\hline
\end{tabular}

BrdU-positive cells were identified by immunostaining and counted in multiple areas in the proliferating zone. Typically, each area consisted of $\sim 0.02 \mathrm{~mm}^{2}$ with $\sim 100$ cells. Values are the mean $\pm \mathrm{SD}$. The number of examined fields $(n=)$ is indicated along with the number of examined sections in parentheses. BrdU-positive cells decreased progressively at successive times after birth in mice expressing Fgfr3 G374, but there was no such decrease in transgenic mice that express MEK1(S218/222E, D32-51). Both mice showed hypercellularity in the proliferating zone. For E16.5, double-transgenic embyros that harbor transgenes of both lines A and B were examined. Statistical analysis was done by the Mann-Whitney U test. (N.S.) Not significant. 
these markers are too subtle to be visualized by immunohistochemistry or in situ hybridization.

Because reduced hypertrophic zone in the growth plate could have been due to accelerated matrix degradation and resorption at the chondro-osseous junction, we examined the expression of MMP9 and the numbers of tartrate-resistant acid phosphatase (TRAP)-positive chondroclasts or osteoclasts (Vu et al. 1998). Immunohistochemical analysis of growth plates showed no difference between wild-type and transgenic mice in MMP9 expression and in the number of TRAP-positive chondroclasts or osteoclasts (data not shown). We also examined the apoptosis of hypertrophic chondrocytes by TUNEL assay. TUNEL-positive hypertrophic chondrocytes were not increased in transgenic mice (data not shown).

\section{The MAPK pathway inhibits chondrocyte hypertrophy in a cell-autonomous manner}

To determine whether the inhibition of chondrocyte hypertrophy via the MAPK pathway is cell autonomous, we crossed transgenic males of line B and wild-type females. As expected, all females in the next generation were heterozygous for the transgene, because the transgene was integrated into the X-chromosome in line B. Also as expected, histological examination of the growth plates of embryos harvested at E15.5 and stained with $\mathrm{X}$-gal showed a mosaic pattern of transgene expression consistent with inactivation of one of the X-chromosomes in females (Fig. 3T; Dandolo et al. 1993; Tan et al. 1993). Chondrocytes from transgenic embryos that stained positive for X-gal were smaller than their neighboring chondrocytes that did not stain positive for X-gal, a finding that was consistent in all of the long bones examined (i.e., humerus, ulna, radius, and femur). These findings indicate that the MAPK pathway inhibited chondrocyte hypertrophy in a cell-autonomous manner and that this inhibition was not mediated by a secondary signal, such as secreted polypeptides or signaling through cell-cell contact.

\section{The MAPK pathway inhibits endochondral} ossification of the cranial base

Because our transgenic mice showed hypoplasia of the cranial base at birth, we examined the endochondral ossification process in the cranial base during embryonic development. To achieve higher expression of the transgene, we crossed males from line A and females from line B. We took this approach for two reasons. On the one hand, mice homozygous for the transgene in line A showed early embryonic lethality that precluded analysis of skeletal development. On the other hand, one of the alleles was inactivated in homozygous females, as a result of integration of the transgene into the $\mathrm{X}$-chromosome in line B. These double-transgenic mice were identified by Southern blot analysis, and higher expression of the transgene was confirmed by X-gal staining of tail cartilage. These mice showed more pronounced midfa- cial hypoplasia and a rounded cranium. Histological examination of the head at E15.5-E17.5 revealed a delay in hypertrophic differentiation of chondrocytes in the cranial base. At E15.5, chondrocytes in the basioccipital bone of wild-type mice were mostly hypertrophic and expressed type X collagen (Fig. 4A,C). In transgenic embryos, chondrocytes in the basioccipital bone remained smaller, and staining for type $\mathrm{X}$ collagen was much weaker than in wild-type littermates (Fig. 4B,D). By E16.5, bone formation was well advanced in the basioccipital bone in wild-type embryos (Fig. 4E). In addition, osteopontin was abundantly expressed in osteoblasts as well as in late-stage hypertrophic chondrocytes (Fig. 4G). Hypertrophic chondrocytes found at the periphery of the basioccipital bone were positive for osteopontin, indicating that these cells were in the late stage of hypertrophic differentiation. In transgenic littermate embryos, osteopontin expression in the cranial base was markedly more restricted (Fig. 4H). Yet there were still numerous chondrocytes that were negative for osteopontin, indicating that these cells were still in an immature stage of differentiation. In contrast, immunostaining showed more extensive Sox9 expression in transgenic animals (Fig. 4I,J). At E17.5, small chondrocytes expressing Sox9 still persisted throughout the basisphenoid bone of transgenic embryos, while the corresponding area in wild-type embryos was totally ossified (Fig. 4K-N). These results indicate that expression of a constitutively active MEK1 mutant in chondrocytes caused persistent expression of Sox9, which is normally down-regulated before hypertrophic differentiation. In light of our recent finding that overexpression of Sox9 inhibits hypertrophic differentiation of chondrocytes (H. Akiyama and B. de Crombrugghe, unpubl.), it is therefore possible that activation of the MAPK pathway in chondrocytes caused persistent expression of Sox9, which in turn inhibited hypertrophic differentiation.

We also examined cell proliferation in the cranial base of double transgenic embryos at E16.5. Chondrocytes in the basisphenoid region that remained small and showed persistent expression of Sox 9 at E16.5 did not show positive staining for BrdU and PCNA, indicating that these cells were not proliferating (Fig. 4O,P; data not shown). It is possible that these cells were already past the proliferative stage and blocked in a stage before hypertrophic differentiation.

Expression of a constitutively active mutant of MEK1 rescues the skeletal overgrowth phenotype

in Fgfr3-deficient mice

Assuming that MAPK signaling negatively regulates bone growth, we hypothesized that skeletal overgrowth in Fgfr3-deficient mice is caused by the reduced activity of the MAPK pathway. To test this hypothesis, we crossed transgenic mice of line A with Fgfr3-deficient mice created by inserting a neomycin cassette into intron 4 of the Fgfr3 locus (Wang et al. 1999). Although these Fgfr3-deficient mice harbor a human achondroplasia mutation, their homozygosity at the Fgfr3 mutant 


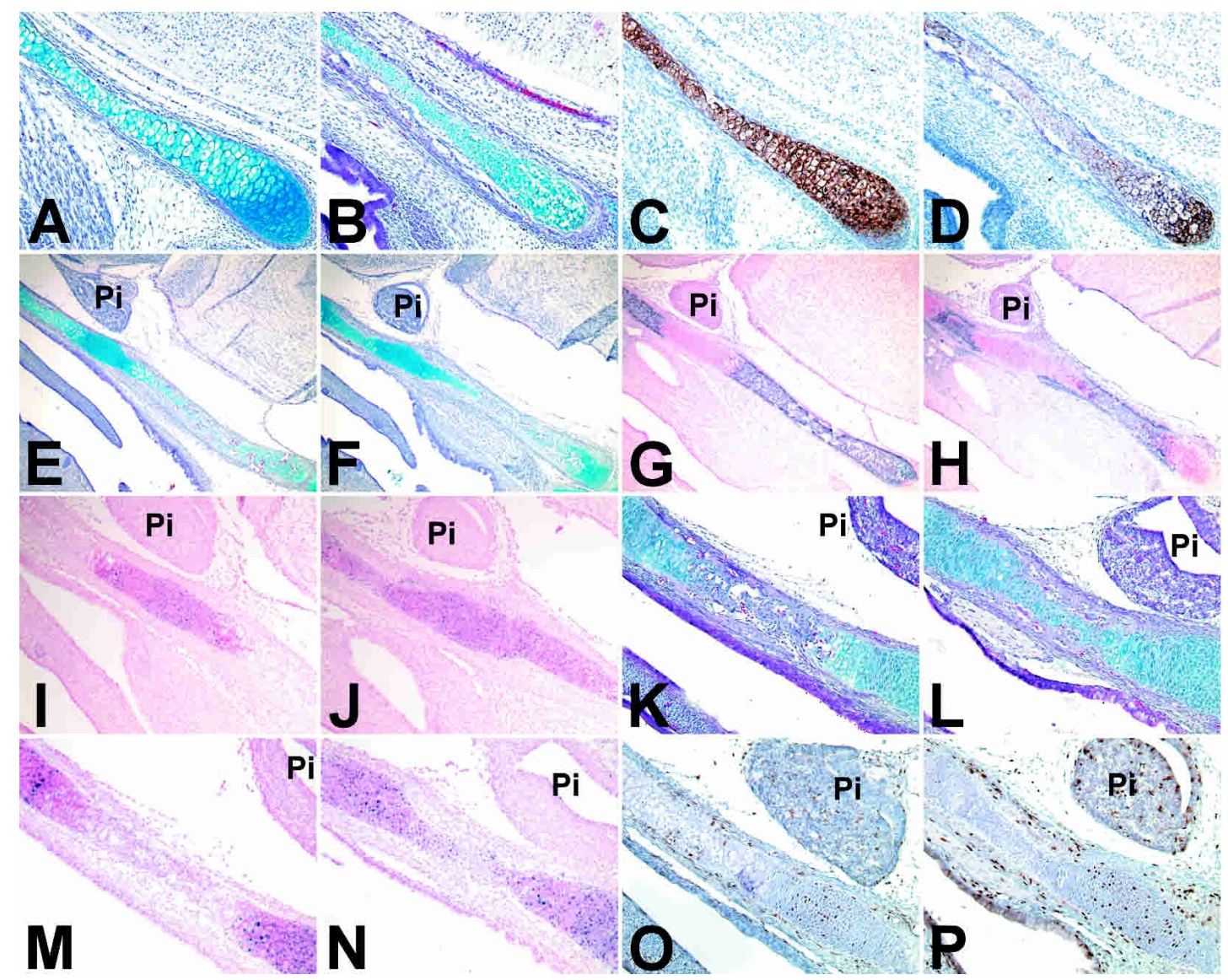

Figure 4. Delayed endochondral ossification of the cranial base in mice expressing MEK1(S218/222E, $\Delta 32-51)$ in chondrocytes. Sagittal sections of the cranial base were stained with alcian blue $(A, B, E, F, K, L)$ or stained immunohistochemically for type $\mathrm{X}$ collagen $(C, D)$, Sox9 $(I, J, M, N)$, osteopontin $(G, H)$, and $\operatorname{BrdU}(O, P) .(A, C)$ The basioccipital region of E15.5 wild-type mice; $(B, D)$ the basioccipital region of E15.5 transgenic mice. (Pi) Pituitary glands. Alcian blue staining of the basioccipital region in E15.5 wild-type $(A)$ and transgenic $(B)$ embryos showed a delay in hypertrophic differentiation of chondrocytes in transgenic mice. Immunohistochemical staining of type X collagen in E15.5 wild-type $(C)$ and transgenic $(D)$ embryos showed reduced staining only in transgenic mice. Delayed ossification of the cranial base was noted at E16.5 for $(E, G)$ wild-type and $(F, H)$ transgenic embryos and at E17.5 for $(K)$ wild-type and $(L)$ transgenic embryos. Transgenic embryos showed persistent expression of Sox9 in chondrocytes at E16.5 for $(I)$ wild-type and $(J)$ transgenic embryos and at E17.5 for $(M)$ wild-type and $(N)$ transgenic embryos. $(G$ and $I),(H$ and $J),(K$ and $M)$, and $(L$ and $N)$ are neighboring sections. There was no obvious difference in BrdU incorporation in chondrocytes of the cranial base at E16.5 for (O) wild-type and $(P)$ transgenic embryos.

allele produces an Fgfr3-null phenotype because insertion of the neomycin cassette interferes with the normal splicing of Fgfr3 mRNA. Consequently, homozygous mutant mice lack the normal Fgfr3 transcript and show skeletal overgrowth. At 3 wk of age, the distance between the proximal and distal growth plates of tibia in homozygous males was $10 \%$ longer than in wild-type controls. Expression of MEK1(S218/222E, $\Delta 32-51$ ) in the chondrocytes of homozygous mutant mice inhibited skeletal overgrowth and led to shortening of tibia to lengths comparable to those seen in wild-type mice (Fig. 5A). Some of the transgenic mice in the Fgfr3-deficient background even showed an achondroplasia-like phenotype (Fig. 5B) and had bones that appeared shorter than their counterparts in wild-type mice (Fig. 5C). Histologically, the growth plates of Fgfr3-deficient mice were characterized by an expanded zone of hypertrophic chon- drocytes. Expression of MEK1(S218/222E, $\Delta 32-51)$ in chondrocytes of Fgfr3-deficient mice reduced the width of hypertrophic zone (Fig. 5D), further supporting the notion that expression of a constitutively active mutant of MEK1 rescued the growth-plate phenotype of Fgfr3deficient mice. Together, these results indicate that expression of a constitutively active mutant of MEK1 was sufficient to overcome the growth-promoting effects of Fgfr3 deficiency and strongly suggest that regulation of longitudinal bone growth by Fgfr3 was mediated at least in part by the MAPK pathway.

Expression of a constitutively active mutant of MEK1 causes achondroplasia-like dwarfism in Stat1-null mice

Because Stat1 has been shown to be involved in the dwarf phenotype caused by activating mutations in 


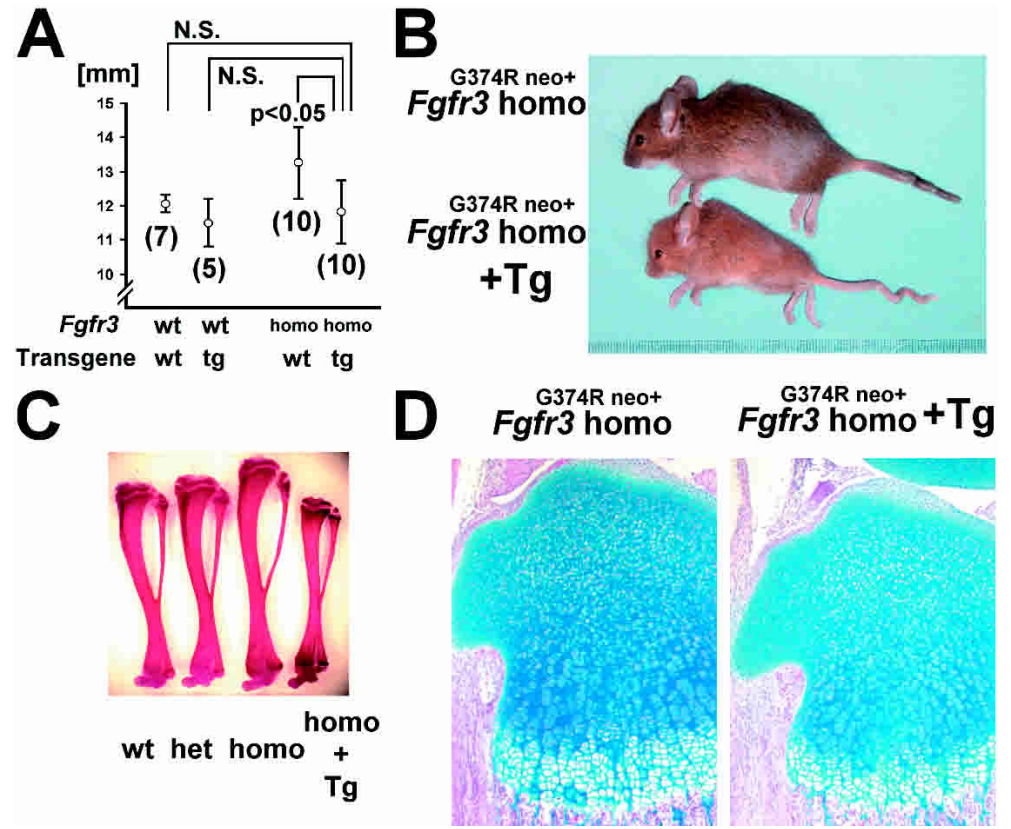

Figure 5. (A) Expression of a constitutively active mutant of MEK1 in the chondrocytes of Fgfr3-deficient mice inhibited skeletal overgrowth. The distance between the proximal and distal growth plates in the tibia was measured in males at 3 wk of age. The tibiae of Fgfr3-deficient mice expressing the MEK1 transgene were shorter than those of Fgfr3deficient mice without the MEK1 transgene $(p<0.05)$. No statistically significant difference was detected between transgenic mice in the Fgfr3-deficient and wild-type backgrounds. The number of samples in each group is indicated in parentheses. Values are the mean \pm SD. (N.S.) Not significant. $(B)$ Gross appearance of 4-wk-old female littermates with or without the transgene in the Fgfr3 homozygous mutant background. $(C)$ The tibia, fibula, and talus of 4-wk-old male littermates. Overgrowth of bones in Fgfr3-deficient mice was inhibited by the expression of a constitutively active mutant of MEK1 in chondrocytes. (D) Alcian blue staining of the proximal tibia of Fgfr3 homozygous mutant male mice with or without the transgene at P5. Expression of a constitutively active mutant of MEK1 in the chondrocytes of Fgfr3-deficient mice reduced the hypertrophic zone in the growth plates.
FGFR3, we crossed transgenic mice expressing MEK1(S218/222E, $\Delta 32-51)$ in chondrocytes and Stat1null mice to determine whether the dwarf phenotype in these transgenic mice was mediated by Stat1. Expression of MEK1(S218/222E, $\Delta 32-51)$ in the chondrocytes of Stat1-null mice caused an achondroplasia-like phenotype similar to that seen in transgenic mice carrying the wild-type Stat1 (Fig. 6A). Skeletal preparations of mice expressing MEK1(S218/222E, $\Delta 32-51)$ in chondrocytes in the Stat1-null background showed a delay in the formation of secondary ossification centers (data not shown). Histological examination of the growth plates showed a narrower hypertrophic zone as determined by type X collagen expression (Fig. 6B; data not shown). At $3 \mathrm{wk}$ of age, the distance between the proximal and distal growth plates of tibia in transgenic mice in the Stat1-null background was significantly shorter than that of wild-type controls in the Stat1-null background $(p<0.01)$ and similar to that of transgenic mice carrying wild-type Stat1 (Fig. 6C). Together, these observations indicate that expression of $\mathrm{MEK} 1(\mathrm{~S} 218 / 222 \mathrm{E}, \Delta 32-51)$ in chondrocytes caused an achondroplasia-like phenotype independent of Stat1.

FGFs increase expression of Sox9, $c$-fos, and p21 in Stat1-null chondrocytes

We next determined whether chondrocytes of the Stat1null mice would respond to FGFs. Primary chondrocytes were isolated from wild type and Stat1-null mice and treated with FGF2 or FGF18. Northern blot analyses showed that Sox9, c-fos, and p21 expression was similarly and strongly up-regulated after FGF treatment in wild-type and Stat1-null chondrocytes, indicating that Stat1-null chondrocytes responded to FGFs and that the expression of these genes was regulated by FGFs in the absence of Stat1 (Fig. 6D,E). In addition, up-regulation of Sox 9 , c-fos, and $p 21$ was strongly inhibited by a specific inhibitor of the MAPK pathway, U0126. Together, these observations indicate that expression of Sox 9, c-fos, and p21 was regulated by FGFs in chondrocytes in the absence of Stat 1 and strongly suggest that the MAPK pathway signaling cascade was functioning normally in Stat1-null chondrocytes.

Human achondroplasia mutation in Fgfr3 causes achondroplasia-like phenotype in Stat1-null mice

Assuming that MAPK signaling acts downstream of Fgfr3 to inhibit bone growth, we hypothesized that loss of Stat1 would not restore the normal bone length in mice expressing achondroplasia mutant of Fgfr3. To test this hypothesis, we crossed mice harboring the Fgfr3 G374R mutation with Stat1-null mice (Fig. 7A). The neomycin cassette was removed by crossing with Zp3Cre transgenic mice. Expression of Fgfr3 G374R in Stat1null mice caused an achondroplasia-like phenotype similar to that seen in mice expressing Fgfr3 G374R in the Stat1 wild-type background (Fig. 7B,C). Histological examination of long bones showed similar reduction of hypertrophic zone in the growth plates and a delay in the formation of secondary ossification centers in mice that express Fgfr3 G374R in the Stat1-null and wild-type background (Fig. 7D). We further examined BrdU incorporation in mice that express Fgfr3 G374R in the Stat1null background. Loss of Stat 1 has been shown to restore the reduced chondrocyte proliferation and normal bone length in transgenic mice that overexpress FGF2 (Sahni et al. 2001). Consistent with the previous report, loss of Stat 1 indeed rescued the reduced BrdU incorporation in 
Figure 6. Expression of a constitutively active mutant of MEK1 in the chondrocytes of Stat1-null mice and the resulting achondroplasia-like phenotype. $(A)$ Gross appearance of 8-d-old male littermates with or without the transgene in the Stat1-null background. Transgenic mice in the Stat1null background showed a rounded cranium and a dwarf phenotype. (B) Alcian blue staining of distal ulnar growth plates of mice shown in A. Stat1-null transgenic mice show reduced size of hypertrophic of chondrocytes and a narrower hypertrophic zone compared with Stat1-null mice without the transgene. $(C)$ The distance between the proximal and distal growth plates in the tibia was measured in males at 3 wk of age. Expression of a constitutively active mutant of MEK1 in chondrocytes caused shortening of tibiae in Stat1-null mice $(p<0.01)$. No statistically significant difference was detected between transgenic mice in the Stat1-null and wild-type backgrounds. The number of samples in each group is indicated in parentheses. (N.S.)

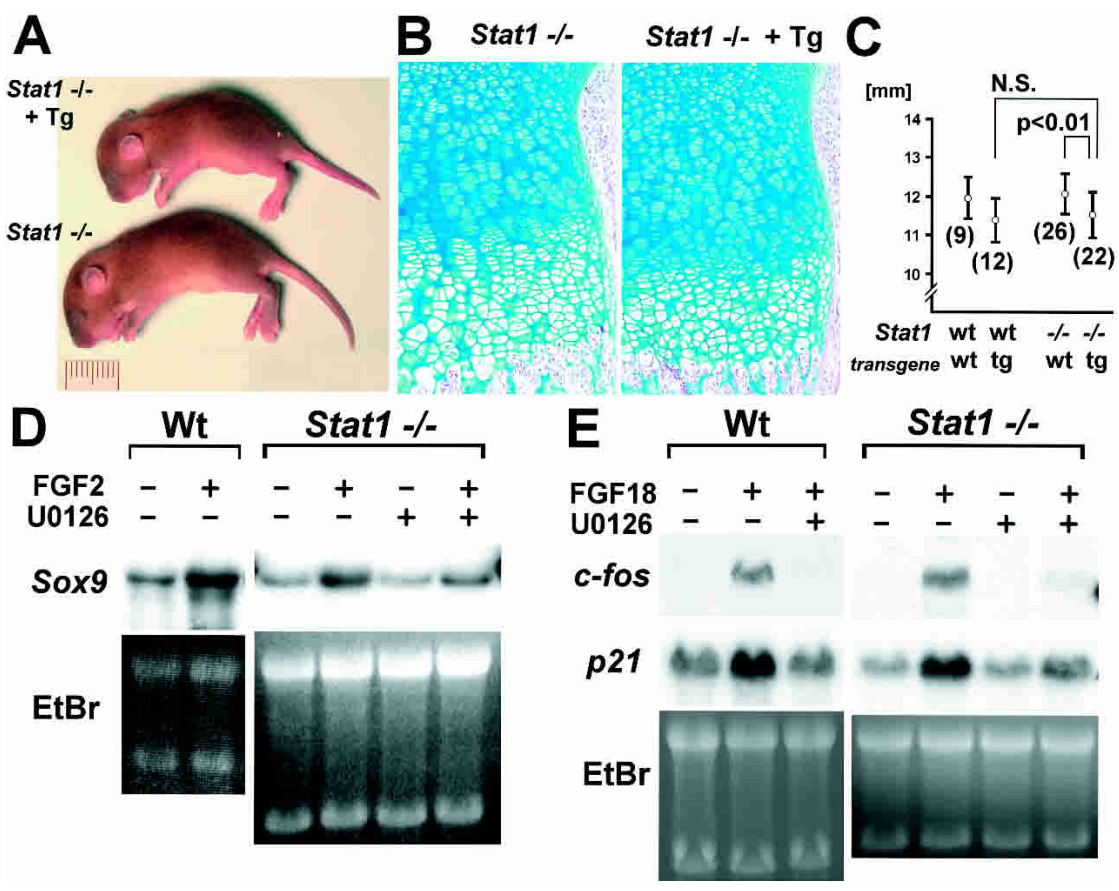
Not significant. $(D, E)$ Primary chondrocytes were isolated from the rib cages of wild-type and Stat1-null mice. Cells were treated with $10 \mathrm{ng} / \mathrm{mL}$ FGF2 or 20 ng/mL FGF18. (D) Sox9 expression was strongly up-regulated at $1 \mathrm{~h}$ after FGF2 treatment both in wild-type and Stat1-null chondrocytes. This up-regulation was strongly inhibited by the MAPK pathway inhibitor, U0126. (E) c-fos and $p 21$ expression were up-regulated at $3 \mathrm{~h}$ after FGF18 treatment both in wild-type and Stat1-null chondrocytes. This up-regulation was strongly inhibited by U0126.

mice that express Fgfr3 G374R (Fig. 7E,F). However, loss of Stat 1 only corrected to a minor extent the shortening of the distance between the proximal and distal growth plates in tibia in mice that express Fgfr3 G374R. The difference between mice expressing Fgfr3 G374R in the Stat1-null and wild-type background was statistically significant in females $(p<0.05)$, but this did not reach statistical significance in males. Together, these observations indicate that Stat 1 indeed mediates antiproliferative effects of Fgfr3 signaling, but loss of Stat1 is not sufficient to rescue the growth inhibitory effects of Fgfr3 G374R.

\section{Discussion}

Activating mutations of FGFR3 have been shown to cause the most common forms of human dwarfism, including achondroplasia and thanatophoric dysplasias, thus indicating that FGFR3 signaling plays a critical role in the regulation of bone growth. Fgfr3 is preferentially expressed in chondrocytes of the proliferating and prehypertrophic zones, whereas Fgfr1 is expressed in chondrocytes of the hypertrophic zone (Deng et al. 1996). Here we show that phosphorylation of MEK1 in growthplate chondrocytes is increased in mice expressing the achondroplasia mutant of Fgfr3. We further show that expression of a constitutively active MEK1 mutant in chondrocytes-although its levels are only $5 \%$ of those of endogenous MEK1-is sufficient to cause dwarfism in transgenic mice. These mice show close similarities to human achondroplasia and thanatophoric dysplasia and their animal models, strongly suggesting that the MAPK pathway plays an important role in the development of dwarfism in FGFR3-related syndromes.

Skeletal measurement of transgenic mice that express MEK1(S218/222E, $\Delta 32-51)$ in chondrocytes showed a reduction in the distance between the proximal and the distal growth plates in long bones. Longitudinal growth of long bones is achieved by the proliferation of chondrocytes, an increase in the size of chondrocytes known as hypertrophic differentiation, and deposition of matrix. Interestingly, in remarkable contrast to mice expressing a human achondroplasia mutant of Fgfr3, proliferation of growth-plate chondrocytes was not inhibited postnatally in transgenic mice that express MEK1/S218/222E, $\Delta 32-$ $51)$ in chondrocytes. It is possible that the MAPK pathway plays no major roles in regulating the cell cycle of growth-plate chondrocytes or that the MAPK pathway requires additional signals, such as Stat1, to regulate chondrocyte proliferation. Histological examination of the growth plates showed reduction in the size of hypertrophic chondrocytes and in the width of the hypertrophic zone and a modest increase in cell density in the proliferating zone. In light of the previous reports that identified an increase in the cellular volume of hypertrophic chondrocytes as a major determinant of the rate of longitudinal bone growth (Breur et al. 1991; Wilsman et al. 1996; Noonan et al. 1998), we speculate that reduction in the size of hypertrophic chondrocytes played a major role in shortening of long bones in these transgenic mice.

Based on our observations indicating that the MAPK 


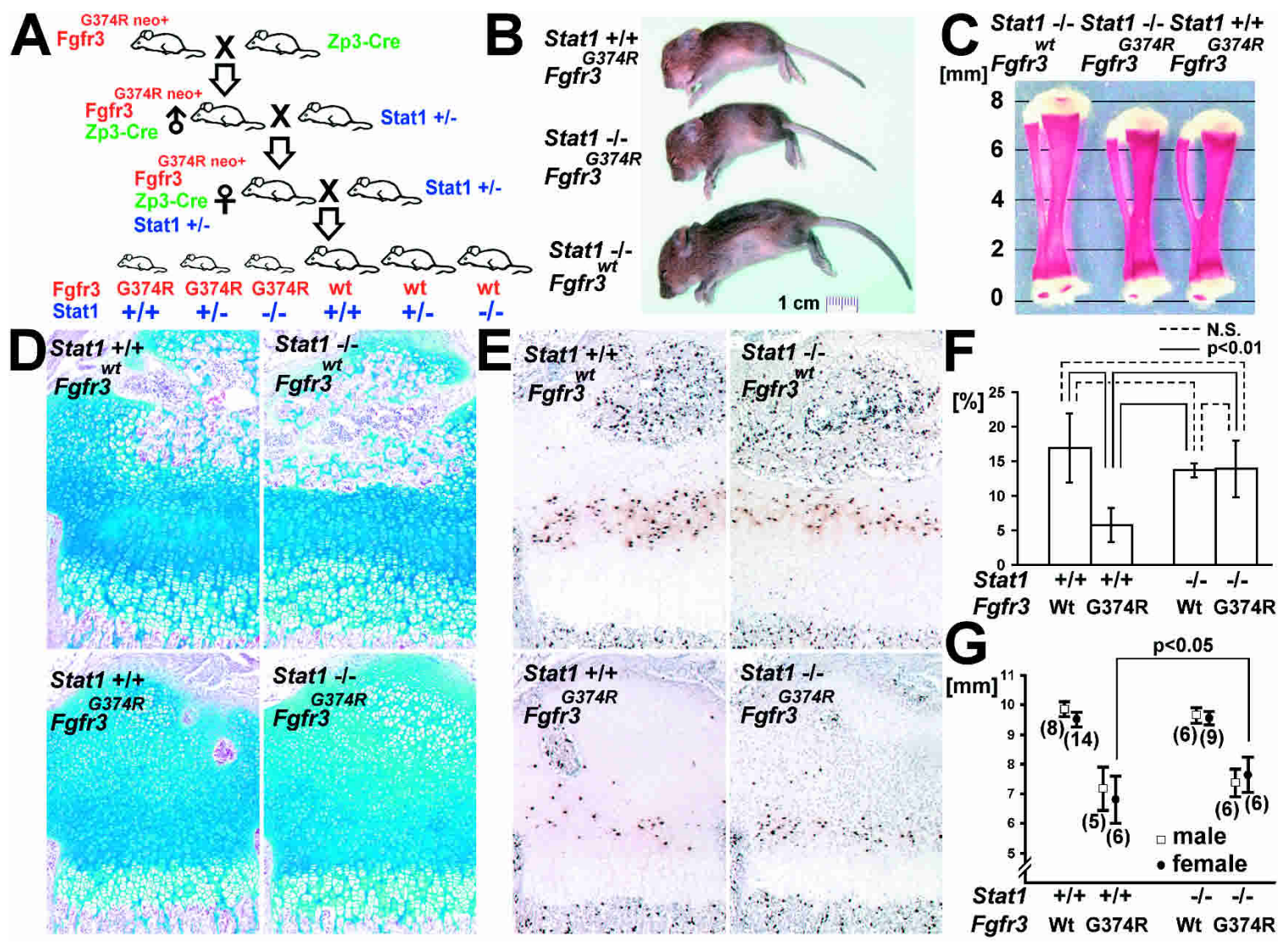

Figure 7. The G374R mutation in Fgfr3 causes an achondroplasia-like phenotype in Stat1-null mice. (A) Mating scheme to express Fgfr3 G374R in Stat1-null mice. Zp3-Cre transgenic mouse line was used to delete the neomycin cassette that interfered with normal splicing of Fgfr3. Zp3-Cre transgenic mice express Cre recombinase in the oocyte. (B) Gross appearance of 14-d-old female littermates with or without the G374R mutation in Fgfr3 in the Stat1-null and wild-type backgrounds. The G374R mutation in Fgfr3 caused an achondroplasia-like phenotype in the Stat1-null background. $(C)$ Alizarin red staining of tibia and fibula of 7-d-old male littermates. The G374R mutation in Fgfr3 caused shortening of long bones and a delay in the formation of secondary ossification centers in the Stat1-null background. (D) Alcian blue staining of proximal tibia of 12-d-old male littermates. Mice carrying the G374R mutation in Fgfr3 in the Stat1-null background showed a reduced hypertrophic zone in the growth plates and a delayed formation of secondary ossification centers. $(E, F)$ BrdU incorporation of proximal tibia of 12-d-old male littermates. BrdU-positive cells were counted and the percentage of positive cells in the proliferating zone was calculated $(F)$. The G374R mutation in Fgfr3 caused a significant reduction in BrdU incorporation in mice carrying wild-type Stat $1(p<0.01)$. There was no statistically significant difference in the number of BrdU-incorporating cells between mice expressing Fgfr3 G374R and mice that were wild-type for Fgfr3 in the Stat1-null background. (N.S.) Not significant. $(G)$ The distance between the proximal and distal growth plates in the tibia was measured in males ( $\square$ ) and females (-) at 2 wk of age. Expression of Fgfr3 G374R caused reduction in the tibial bone length both in mice that were wild type for Stat1 and Stat1-null mice. Loss of Stat1 corrected the bone length to a minor extent.

pathway negatively regulates bone growth, we hypothesized that reduced activity of the MAPK pathway plays a major role in the skeletal overgrowth of Fgfr3-null mice. Consistent with this hypothesis, expression of a constitutively active mutant of MEK1 in chondrocytes of Fgfr3-deficient mice inhibited skeletal overgrowth, indicating that activation of the MAPK pathway is sufficient to overcome the growth-promoting effects of Fgfr3 deficiency. In addition, expression of a constitutively active mutant of MEK1 in chondrocytes of Fgfr3-deficient mice corrected the expanded hypertrophic zone in these mice. These observations support the notion that the expanded hypertrophic zone and skeletal overgrowth in Fgfr3-null mice are caused by reduced activity of the MAPK pathway. These observations also suggest that
Fgfr3 signaling regulates differentiation of growth-plate chondrocytes through the MAPK pathway.

Mouse models of achondroplasia and thanatophoric dysplasia have shown delayed hypertrophic differentiation of chondrocytes (Naski et al. 1998; Iwata et al. 2000; Segev et al. 2000), strongly suggesting that overall effects of Fgfr3 signaling are to inhibit hypertrophic differentiation. Consistent with these observations, we observed a delay in hypertrophic chondrocyte differentiation and a reduction in the size of hypertrophic chondrocytes both in mice that express an achondroplasia mutant of Fgfr3 and in transgenic mice that express a constitutively active mutant of MEK1. Interestingly, gene expression changes consistent with some aspects of hypertrophic differentiation have been reported in FGF-treated bone 
explants and in a chondrocytic cell line RCS (Minina et al. 2002; Dailey et al. 2003). It is possible that excess FGF signaling uncouples morphological hypertrophic changes of chondrocytes from some of the gene expression changes that are normally associated with hypertrophic differentiation.

Recently Stat 1 has been shown to mediate FGF signaling in chondrocytes. Loss of Stat 1 rescued the decreased chondrocyte proliferation and restored the bone length in transgenic mice that overexpress FGF2 under the control of a phosphoglycerate kinase promoter (Sahni et al. 2001). To examine the possible interaction between the MAPK pathway and Statl, we crossed transgenic mice that express a constitutively active mutant of MEK1 in chondrocytes with Stat1-null mice. Transgenic mice expressing a constitutively active mutant of MEK1 in chondrocytes in the Stat1-null background showed a reduced hypertrophic zone in the growth plates and delayed formation of secondary ossification centers. In addition, loss of Stat1 did not affect the growth-inhibitory effects of the MAPK pathway. These observations indicate that Stat 1 is not a major downstream mediator of MAPK signaling in growth-plate chondrocytes. We also examined FGF activation of MAPK in Stat1-null primary chondrocytes. FGF18 treatment of Stat1-null chondrocytes caused prolonged phosphorylation of ERK1, ERK2, and MEK1 (data not shown). FGF2 or FGF18 treatment of wild-type and Stat1-null chondrocytes caused similar up-regulation of $\operatorname{Sox} 9$, c-fos, and $p 21$, which was inhibited by an inhibitor of the MAPK pathway, indicating activation of the MAPK pathway by FGFs is independent of Stat1. These observations strongly suggest that the effects of the MAPK pathway on growth-plate chondrocytes are independent of Stat1.

Assuming that the MAPK pathway acts independently of Stat1, we hypothesized that loss of Stat1 would not rescue the dwarf phenotype caused by activating mutations in Fgfr3. Indeed, loss of Stat1 only corrected to a minor extent the bone length of mice expressing Fgfr3 G374R, despite restoration of BrdU incorporation. These results indicate that Stat 1 mediates the antiproliferative effects of Fgfr3 G374R, but also indicate the presence of additional mechanisms for the growth inhibition by Fgfr3 G374R. Expression of Fgfr3 G374R in Stat1-null mice caused a reduced hypertrophic zone and a delay in the formation of secondary ossification centers, which could be a result of increased activity of the MAPK pathway.

In a study of 28-d-old rats, it has been estimated that in the proximal tibia, $59 \%$ of bone growth is contributed by hypertrophy of chondrocytes, $32 \%$ by matrix synthesis, and $9 \%$ by cellular division (Wilsman et al. 1996). Although these values are likely to vary depending on the bone, age, and species, our results are consistent with the idea that reduced hypertrophy of chondrocytes plays a major role in the reduced bone growth in mice that express Fgfr3 G374R. Because FGF is a potent stimulator of the MAPK pathway, and MAPK signaling inhibits hypertrophic differentiation, we speculate that the increased activity of the MAPK pathway played an important role in the dwarf phenotype in Stat1-null mice that express Fgfr3 G374R. In addition to Stat1 and the MAPK pathway, FGFs stimulate various other pathways including the activity of other Stat family proteins. Activation of Stat5a and Stat $5 b$ has been reported in mice that harbor a thanatophoric dysplasia mutation in Fgfr3 ( $\mathrm{Li}$ et al. 1999). It is possible that other pathways including Stat5a and Stat5b may also have played a role in the dwarf phenotype in Stat1-null mice that express Fgfr3 G374R. The roles of each of those proteins in Fgfr3 signaling require further investigation.

Our observations with mice expressing Fgfr3 G374R in the Stat1-null background are apparently different from the previous report that described the restoration by inactivation of Statl of normal bone length in mice overexpressing FGF2. This apparent discrepancy may be explained by the difference in the level of activation of FGF signaling in the two mouse models. The dwarf phenotype of transgenic mice that overexpress FGF2 under the phosphoglycerate kinase promoter was apparently much milder than that of mice expressing Fgfr3 G374R /Coffin et al. 1995; Wang et al. 1999; Sahni et al. 2001). Hence, it is possible that activation of Fgfr3 signaling is more pronounced in mice expressing Fgfr3 G374R than in mice harboring an FGF2 transgene. Perhaps because of differences in levels of activity of Fgfr3, pathways other than Stat 1 are less activated in mice carrying the FGF2 transgene than in mice expressing Fgfr3 G374R.

Because expression of a constitutively active mutant of MEK1 in chondrocytes inhibits hypertrophic chondrocyte differentiation and causes a phenotype similar to the most common forms of human dwarfisms, downstream targets of the MAPK pathway in chondrocytes are of considerable interest. We have previously reported that FGFs increase Sox 9 expression in chondrocytes in culture. This increase in Sox9 expression can be inhibited by a specific inhibitor of MEK1/2, strongly suggesting that up-regulation of Sox9 expression by FGFs is mediated by the MAPK pathway. In the growth plates, Sox 9 mRNA is expressed in all chondrocytes except hypertrophic chondrocytes. Sox 9 heterozygous mutant mice show a widening of the zone of hypertrophic chondrocytes in the growth plates and premature mineralization of endochondral bones, strongly suggesting that a 50\% decrease in Sox9 results in acceleration of chondrocyte maturation. In addition, the phenotype of mice in which Sox9 is inactivated after mesenchymal condensation using the Cre-loxP system is consistent with the idea that once $\operatorname{Sox} 9$ was inactivated, chondrocytes rapidly converted into hypertrophic chondrocytes (Akiyama et al. 2002). Together, these observations support the hypothesis that increased activity of FGFR3 and the MAPK pathway would up-regulate $\operatorname{Sox} 9$ expression, which in turn would inhibit hypertrophic differentiation of chondrocytes. Although we did not observe a difference in Sox 9 expression levels in transgenic mice that express a constitutively active mutant of MEK1 in chondrocytes at multiple time points between E16.5 and P24, in mice expressing Fgfr3 G374R, and in Fgfr3-deficient mice at P3 and P10 in immunohistochemistry (data not shown), 


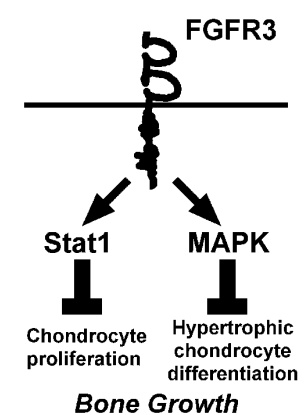

Figure 8. Model for downstream signaling pathways that mediate the inhibitory effects of FGFR3 signaling on bone growth. The MAPK pathway mediates inhibition of hypertrophic chondrocyte differentiation, whereas Stat 1 mediates inhibition of chondrocyte proliferation.

it is still possible that subtle differences in Sox9 expression could have affected chondrocyte differentiation in these animals. Indeed, recent genetic experiments in our laboratory have shown that even a modest increase in Sox9 expression in chondrocytes, which cannot be visualized by immunohistochemistry using anti-Sox 9 antibody, causes a delay in hypertrophic differentiation $(\mathrm{H}$. Akiyama and B. de Crombrugghe, unpubl.). Expression of a constitutively active mutant of MEK1 in chondrocytes could cause the persistent expression of Sox9 in chondrocytes in the cranial base that was observed, implying that the MAPK pathway might have a role in inhibiting down-regulation of Sox 9 that normally occurs at the time of hypertrophic differentiation.

Collectively, our observations indicate that the MAPK pathway inhibits hypertrophic chondrocyte differentiation and longitudinal bone growth without affecting chondrocyte proliferation. Expression of a constitutively active mutant of MEK1 in chondrocytes of transgenic mice was sufficient to cause a dwarf phenotype similar to human achondroplasia, strongly suggesting that increased activity of the MAPK pathway plays an important role in the development of the dwarf phenotype in achondroplasia and thanatophoric dysplasia. In contrast, loss of Stat 1 rescued the reduced chondrocyte proliferation in mice that express an achondroplasia mutant of Fgfr3, but failed to rescue the reduced hypertrophic zone in the growth plates and a delay in the formation of secondary ossification centers, and only produced a minor correction in bone length. Based on our observations, we propose a model in which Fgfr3 signaling uses the MAPK pathway to inhibit chondrocyte hypertrophy and Stat 1 to inhibit chondrocyte proliferation (Fig. 8). Further analysis of downstream targets of the MAPK pathway as well as Statl should provide important insights into the pathomechanisms of dwarfism syndromes caused by activating mutations of FGFR3.

\section{Materials and methods}

Mice

To induce the expression of a constitutively active mutant of MEK1(S218/222E, $\Delta 32-51)$ in chondrocytes, the MEK1 cDNA contained in pFC-MEK1 (Stratagene) was released by enzymatic digestion and cloned into a vector containing $3 \mathrm{~kb}$ of the Col2a 1 promoter and $3.02 \mathrm{~kb}$ of intron 1 sequences (Zhou et al. 1995). Nucleotides encoding a 16-amino-acid sequence (MDYKDDDDKGILQIGS) containing an initiating methionine and a Flag epitope were added to the $5^{\prime}$-end of the mutant $M E K 1 \mathrm{cDNA}$ to facilitate identification of the protein. The $L a c Z$ gene preceded by an internal ribosome entry site was placed downstream from the MEK1 cDNA. The construct was microinjected into the pronuclei of fertilized C57BL/ $6 \times \mathrm{DBA} / 2$ hybrid eggs to generate transgenic mice. Transgenic founders and double-transgenic mice that harbor transgenes of both line A and line B were identified by Southern blot analysis using a probe for LacZ. Routine genotyping was done by PCR using primers 5 '-CGAT GAGCGTGGTGGTTATGC-3' and 5'-AACGCCTCGAATCA GCAAC-3', which amplify 226 bp of LacZ. Mice harboring the G374R mutation in Fgfr3 that corresponds to human achondroplasia mutation G380R, Zp3-Cre transgenic mice, and Prx1Cre transgenic mice were described previously (Lewandoski et al. 1997; Wang et al. 1999; Akiyama et al. 2002; Logan et al. 2002). Stat1-null mice were purchased from Taconic (Meraz et al. 1996).

\section{Cell cultures and Northern and Western blot analyses}

Primary chondrocytes were isolated from the rib cages of newborn mice as previously described (Lefebvre et al. 1994). Cells were grown to confluence and treated with FGF2 (Peprotech), FGF18 (R\&D), EGF (Sigma), PDGF-BB (Peprotech), TGF- $\beta$ (Life Technologies), and IGF-I (Peprotech). Northern blot and Western blot analyses were done as previously described (Murakami et al. 2000). For Western analysis, the following antibodies were used; Flag M5 (Sigma), MEK1 (SantaCruz), phospho-MEK1/2 (Cell Signaling Technology), ERK1 (SantaCruz), phosphoERK1,2 (Cell Signaling Technology), Sox9 (SantaCruz), and cFos (SantaCruz).

\section{Skeletal preparations}

Skeletal morphology was analyzed by alizarin red and alcian blue staining. To measure bone length, isolated bones were laid next to a ruler and photographed using a digital camera. The distance between epiphyseal growth plates was calculated using photo editing software.

\section{Histological examination}

For histological analysis, tissues were fixed in 10\% formalin and embedded in paraffin. Postnatal tissues were demineralized in 0.5 M EDTA before embedding. Then 7- $\mu$ m-thick sections were stained with hematoxylin, eosin, and alcian blue. Immunohistochemical staining was performed using a peroxidase-conjugated polymer (Zymed) and tetramethylbenzidine or MM biotinylation kit (Biocare). The following antibodies were used: Sox9 (Lefebvre et al. 1997), MEK1 (Chemicon), phospho-MEK1/2 (Cell Signaling Technology, Calbiochem), MMP9 (Chemicon), MMP13 (Chemicon), osteopontin (R\&D), Runx2 (SantaCruz), and type X collagen (Quartett). RNA in situ hybridization was done using a digoxigenin- or FITC-labeled riboprobe and TSA system (Perkin Elmer) or ${ }^{35} \mathrm{~S}$-UTP labeled riboprobes. For examining cell proliferation, mice were injected intraperitoneally with BrdU. Embryos were harvested $4 \mathrm{~h}$ after injection. For postnatal analysis, mice were killed $2.5 \mathrm{~h}$ after injection. Cells that incorporated BrdU were identified using a BrdU staining kit (Zymed). A PCNA staining kit (Zymed) was used to examine 
PCNA expression. TUNEL analysis was performed using the ApopTag Plus peroxidase in situ apoptosis detection kit (Intergen).

\section{Acknowledgments}

We thank Chu-Xia Deng (National Institutes of Health, Bethesda, MD), Stephen J. Elledge (Baylor College of Medicine, Houston, TX), and Andrew P. McMahon (Harvard University, Cambridge, MA) for Fgfr3, p21, and Indian hedgehog probes; James Martin (Institute of Biosciences and Technology, Houston, TX) for Prx1-Cre transgenic mice; and Kazuhisa Nakashima for critically reading the manuscript. This work was funded by NIH grants PO1 AR42919 to B.d.C.; the G. Harold \& Leila Y. Mathers Charitable Foundation to B.d.C.; and an Arthritis Investigator Award of the Arthritis Foundation to S.M. We also acknowledge NIH grant CA16672 for DNA sequence analysis.

The publication costs of this article were defrayed in part by payment of page charges. This article must therefore be hereby marked "advertisement" in accordance with 18 USC section 1734 solely to indicate this fact.

\section{References}

Akiyama, H., Chaboissier, M.C., Martin, J.F., Schedl, A., and de Crombrugghe, B. 2002. The transcription factor Sox9 has essential roles in successive steps of the chondrocyte differentiation pathway and is required for expression of Sox 5 and Sox6. Genes \& Dev. 16: 2813-2828.

Bellus, G.A., McIntosh, I., Smith, E.A., Aylsworth, A.S., Kaitila, I., Horton, W.A., Greenhaw, G.A., Hecht, J.T., and Francomano, C.A. 1995. A recurrent mutation in the tyrosine kinase domain of fibroblast growth factor receptor 3 causes hypochondroplasia. Nat. Genet. 10: 357-359.

Bi, W., Deng, J.M., Zhang, Z., Behringer, R.R., and de Crombrugghe, B. 1999. Sox9 is required for cartilage formation. Nat. Genet. 22: 85-89.

Bi, W., Huang, W., Whitworth, D.J., Deng, J.M., Zhang, Z., Behringer, R.R., and de Crombrugghe, B. 2001. Haploinsufficiency of Sox 9 results in defective cartilage primordia and premature skeletal mineralization. Proc. Natl. Acad. Sci. 98: 6698-6703.

Breur, G.J., VanEnkevort, B.A., Farnum, C.E., and Wilsman, N.J. 1991. Linear relationship between the volume of hypertrophic chondrocytes and the rate of longitudinal bone growth in growth plates. J. Orthop. Res. 9: 348-359.

Chen, L., Li, C., Qiao, W., Xu, X., and Deng, C. 2001. A $\operatorname{Ser}(365) \rightarrow$ Cys mutation of fibroblast growth factor receptor 3 in mouse downregulates Ihh/PTHrP signals and causes severe achondroplasia. Hum. Mol. Genet. 10: 457-465.

Coffin, J.D., Florkiewicz, R.Z., Neumann, J., Mort-Hopkins, T., Dorn II, G.W., Lightfoot, P., German, R., Howles, P.N., Kier, A., O'Toole, B.A., et al. 1995. Abnormal bone growth and selective translational regulation in basic fibroblast growth factor (FGF-2) transgenic mice. Mol. Biol. Cell 6: 1861-1873.

Colvin, J.S., Bohne, B.A., Harding, G.W., McEwen, D.G., and Ornitz, D.M. 1996. Skeletal overgrowth and deafness in mice lacking fibroblast growth factor receptor 3. Nat. Genet. 12: 390-397.

Coso, O.A., Chiariello, M., Yu, J.C., Teramoto, H., Crespo, P., $\mathrm{Xu}$, N., Miki, T., and Gutkind, J.S. 1995. The small GTPbinding proteins Rac1 and Cdc42 regulate the activity of the JNK/SAPK signaling pathway. Cell 81: 1137-1146.

Dailey, L., Laplantine, E., Priore, R., and Basilico, C. 2003. A network of transcriptional and signaling events is activated by FGF to induce chondrocyte growth arrest and differentiation. J. Cell Biol. 161: 1053-1066.

Dandolo, L., Stewart, C.L., Mattei, M.G., and Avner, P.R. 1993. Inactivation of an X-linked transgene in murine extraembryonic and adult tissues. Development 118: 641-649.

Debiais, F., Lemonnier, J., Hay, E., Delannoy, P., Caverzasio, J., and Marie, P.J. 2001. Fibroblast growth factor-2 (FGF-2) increases $\mathrm{N}$-cadherin expression through protein kinase $\mathrm{C}$ and Src-kinase pathways in human calvaria osteoblasts. J. Cell Biochem. 81: 68-81.

Delezoide, A.L., Benoist-Lasselin, C., Legeai-Mallet, L., Le Merrer, M., Munnich, A., Vekemans, M., and Bonaventure, J. 1998. Spatio-temporal expression of FGFR 1, 2 and 3 genes during human embryo-fetal ossification. Mech. Dev. 77: 1930.

Deng, C., Wynshaw-Boris, A., Zhou, F., Kuo, A., and Leder, P. 1996. Fibroblast growth factor receptor 3 is a negative regulator of bone growth. Cell 84: 911-921.

Garofalo, S., Kliger-Spatz, M., Cooke, J.L., Wolstin, O., Lunstrum, G.P., Moshkovitz, S.M., Horton, W.A., and Yayon, A. 1999. Skeletal dysplasia and defective chondrocyte differentiation by targeted overexpression of fibroblast growth factor 9 in transgenic mice. J. Bone Miner. Res. 14: 1909-1915.

Iwata, T., Chen, L., Li, C., Ovchinnikov, D.A., Behringer, R.R., Francomano, C.A., and Deng, C.X. 2000. A neonatal lethal mutation in FGFR3 uncouples proliferation and differentiation of growth plate chondrocytes in embryos. Hum. Mol. Genet. 9: 1603-1613.

Iwata, T., Li, C.L., Deng, C.X., and Francomano, C.A. 2001. Highly activated Fgfr3 with the K644M mutation causes prolonged survival in severe dwarf mice. Hum. Mol. Genet. 10: 1255-1264.

Kong, M., Wang, C.S., and Donoghue, D.J. 2002. Interaction of fibroblast growth factor receptor 3 and the adapter protein SH2-B. A role in STAT5 activation. J. Biol. Chem. 277: 15962-15970.

Lefebvre, V., Garofalo, S., Zhou, G., Metsaranta, M., Vuorio, E., and de Crombrugghe, B. 1994. Characterization of primary cultures of chondrocytes from type II collagen/ $\beta$-galactosidase transgenic mice. Matrix Biol. 14: 329-335.

Lefebvre, V., Huang, W., Harley, V.R., Goodfellow, P.N., and de Crombrugghe, B. 1997. SOX9 is a potent activator of the chondrocyte-specific enhancer of the pro $\alpha 1(\mathrm{II})$ collagen gene. Mol. Cell Biol. 17: 2336-2346.

Legeai-Mallet, L., Benoist-Lasselin, C., Delezoide, A.L., Munnich, A., and Bonaventure, J. 1998. Fibroblast growth factor receptor 3 mutations promote apoptosis but do not alter chondrocyte proliferation in thanatophoric dysplasia. J. Biol. Chem. 273: 13007-13014.

Lewandoski, M., Wassarman, K.M., and Martin, G.R. 1997. Zp3-Cre, a transgenic mouse line for the activation or inactivation of loxP-flanked target genes specifically in the female germ line. Curr. Biol. 7: 148-151.

Li, C., Chen, L., Iwata, T., Kitagawa, M., Fu, X.Y., and Deng, C.X. 1999. A Lys644Glu substitution in fibroblast growth factor receptor 3 (FGFR3) causes dwarfism in mice by activation of STATs and ink4 cell cycle inhibitors. Hum. Mol. Genet. 8: 35-44.

Liu, Z., Xu, J., Colvin, J.S., and Ornitz, D.M. 2002. Coordination of chondrogenesis and osteogenesis by fibroblast growth factor 18. Genes \& Dev. 16: 859-869.

Logan, M., Martin, J.F., Nagy, A., Lobe, C., Olson, E.N., and Tabin, C.J. 2002. Expression of Cre recombinase in the developing mouse limb bud driven by a Prxl enhancer. Genesis 33: $77-80$. 
Lu, Q. and Zheng, C. 1998. Production of full-length, biologically active MEK1 ${ }^{\mathrm{WT}}$ and MEK1 ${ }^{\mathrm{CA}}$. Strategies 10: 46-47.

Mansour, S.J., Matten, W.T., Hermann, A.S., Candia, J.M., Rong, S., Fukasawa, K., Vande Woude, G.F., and Ahn, N.G. 1994. Transformation of mammalian cells by constitutively active MAP kinase kinase. Science 265: 966-970.

Meraz, M.A., White, J.M., Sheehan, K.C., Bach, E.A., Rodig, S.J., Dighe, A.S., Kaplan, D.H., Riley, J.K., Greenlund, A.C., Campbell, D., et al. 1996. Targeted disruption of the Stat 1 gene in mice reveals unexpected physiologic specificity in the JAK-STAT signaling pathway. Cell 84: 431-442.

Minina, E., Kreschel, C., Naski, M.C., Ornitz, D.M., and Vortkamp, A. 2002. Interaction of FGF, Ihh/Pthlh, and BMP signaling integrates chondrocyte proliferation and hypertrophic differentiation. Dev. Cell 3: 439-449.

Murakami, S., Kan, M., McKeehan, W.L., and de Crombrugghe, B. 2000. Up-regulation of the chondrogenic Sox9 gene by fibroblast growth factors is mediated by the mitogen-activated protein kinase pathway. Proc. Natl. Acad. Sci. 97: 1113-1118.

Naski, M.C., Colvin, J.S., Coffin, J.D., and Ornitz, D.M. 1998. Repression of hedgehog signaling and BMP4 expression in growth plate cartilage by fibroblast growth factor receptor 3 . Development 125: 4977-4988.

Noonan, K.J., Hunziker, E.B., Nessler, J., and Buckwalter, J.A. 1998. Changes in cell, matrix compartment, and fibrillar collagen volumes between growth-plate zones. J. Orthop. Res. 16: $500-508$.

Ohbayashi, N., Shibayama, M., Kurotaki, Y., Imanishi, M., Fujimori, T., Itoh, N., and Takada, S. 2002. FGF18 is required for normal cell proliferation and differentiation during osteogenesis and chondrogenesis. Genes \& Dev. 16: 870-879.

Peters, K., Ornitz, D., Werner, S., and Williams, L. 1993. Unique expression pattern of the FGF receptor 3 gene during mouse organogenesis. Dev. Biol. 155: 423-430.

Ronchetti, D., Greco, A., Compasso, S., Colombo, G., Dell'Era, P., Otsuki, T., Lombardi, L., and Neri, A. 2001. Deregulated FGFR3 mutants in multiple myeloma cell lines with $\mathrm{t}(4 ; 14)$ : Comparative analysis of $\mathrm{Y} 373 \mathrm{C}, \mathrm{K} 650 \mathrm{E}$ and the novel G384D mutations. Oncogene 20: 3553-3562.

Rousseau, F., Bonaventure, J., Legeai-Mallet, L., Pelet, A., Rozet, J.M., Maroteaux, P., Le Merrer, M., and Munnich, A. 1994. Mutations in the gene encoding fibroblast growth factor receptor-3 in achondroplasia. Nature 371: 252-254.

Rousseau, F., Saugier, P., Le Merrer, M., Munnich, A., Delezoide, A.L., Maroteaux, P., Bonaventure, J., Narcy, F., and Sanak, M. 1995. Stop codon FGFR3 mutations in thanatophoric dwarfism type 1. Nat. Genet. 10: 11-12.

Sahni, M., Ambrosetti, D.C., Mansukhani, A., Gertner, R., Levy, D., and Basilico, C. 1999. FGF signaling inhibits chondrocyte proliferation and regulates bone development through the STAT-1 pathway. Genes \& Dev. 13: 1361-1366.

Sahni, M., Raz, R., Coffin, J.D., Levy, D., and Basilico, C. 2001. STAT1 mediates the increased apoptosis and reduced chondrocyte proliferation in mice overexpressing FGF2. Development 128: 2119-2129.

Segev, O., Chumakov, I., Nevo, Z., Givol, D., Madar-Shapiro, L., Sheinin, Y., Weinreb, M., and Yayon, A. 2000. Restrained chondrocyte proliferation and maturation with abnormal growth plate vascularization and ossification in human FGFR-3(G380R) transgenic mice. Hum. Mol. Genet. 9: 249258.

Shiang, R., Thompson, L.M., Zhu, Y.Z., Church, D.M., Fielder, T.J., Bocian, M., Winokur, S.T., and Wasmuth, J.J. 1994. Mutations in the transmembrane domain of FGFR3 cause the most common genetic form of dwarfism, achondroplasia.
Cell 78: 335-342.

Shimoaka, T., Ogasawara, T., Yonamine, A., Chikazu, D., Kawano, H., Nakamura, K., Itoh, N., and Kawaguchi, H. 2002. Regulation of osteoblast, chondrocyte, and osteoclast functions by fibroblast growth factor (FGF)-18 in comparison with FGF-2 and FGF-10. J. Biol. Chem. 277: 7493-7500.

Su, W.C., Kitagawa, M., Xue, N., Xie, B., Garofalo, S., Cho, J., Deng, C., Horton, W.A., and Fu, X.Y. 1997. Activation of Stat 1 by mutant fibroblast growth-factor receptor in thanatophoric dysplasia type II dwarfism. Nature 386: 288-292.

Tan, S.S., Williams, E.A., and Tam, P.P. 1993. X-Chromosome inactivation occurs at different times in different tissues of the post-implantation mouse embryo. Nat. Genet. 3: 170174.

Tavormina, P.L., Shiang, R., Thompson, L.M., Zhu, Y.Z., Wilkin, D.J., Lachman, R.S., Wilcox, W.R., Rimoin, D.L., Cohn, D.H., and Wasmuth, J.J. 1995. Thanatophoric dysplasia (types I and II) caused by distinct mutations in fibroblast growth factor receptor 3. Nat. Genet. 9: 321-328.

Vu, T.H., Shipley, J.M., Bergers, G., Berger, J.E., Helms, J.A., Hanahan, D., Shapiro, S.D., Senior, R.M., and Werb, Z. 1998. MMP-9/gelatinase B is a key regulator of growth plate angiogenesis and apoptosis of hypertrophic chondrocytes. Cell 93: 411-422.

Wang, Y., Spatz, M.K., Kannan, K., Hayk, H., Avivi, A., Gorivodsky, M., Pines, M., Yayon, A., Lonai, P., and Givol, D. 1999. A mouse model for achondroplasia produced by targeting fibroblast growth factor receptor 3. Proc. Natl. Acad. Sci. 96: 4455-4460.

Wilsman, N.J., Farnum, C.E., Leiferman, E.M., Fry, M., and Barreto, C. 1996. Differential growth by growth plates as a function of multiple parameters of chondrocytic kinetics. J. Orthop. Res. 14: 927-936.

Zhou, G., Garofalo, S., Mukhopadhyay, K., Lefebvre, V., Smith, C.N., Eberspaecher, H., and de Crombrugghe, B. 1995. A 182 bp fragment of the mouse pro $\alpha 1$ (II) collagen gene is sufficient to direct chondrocyte expression in transgenic mice. J. Cell Sci. 108: 3677-3684. 


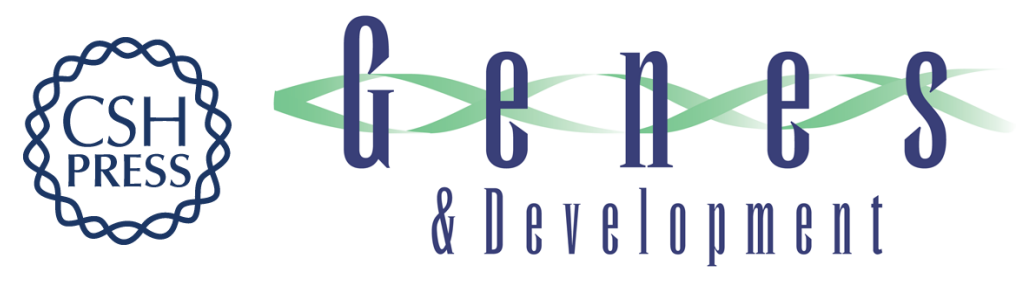

\section{Constitutive activation of MEK1 in chondrocytes causes Stat1-independent achondroplasia-like dwarfism and rescues the Fgfr3-deficient mouse phenotype}

Shunichi Murakami, Gener Balmes, Sandra McKinney, et al.

Genes Dev. 2004, 18:

Access the most recent version at doi:10.1101/gad.1179104

$\begin{array}{ll}\text { References } & \begin{array}{l}\text { This article cites } 49 \text { articles, } 18 \text { of which can be accessed free at: } \\ \text { http://genesdev.cshlp.org/content/18/3/290.full.html\#ref-list-1 }\end{array}\end{array}$

License

Email Alerting Receive free email alerts when new articles cite this article - sign up in the box at the top Service right corner of the article or click here.

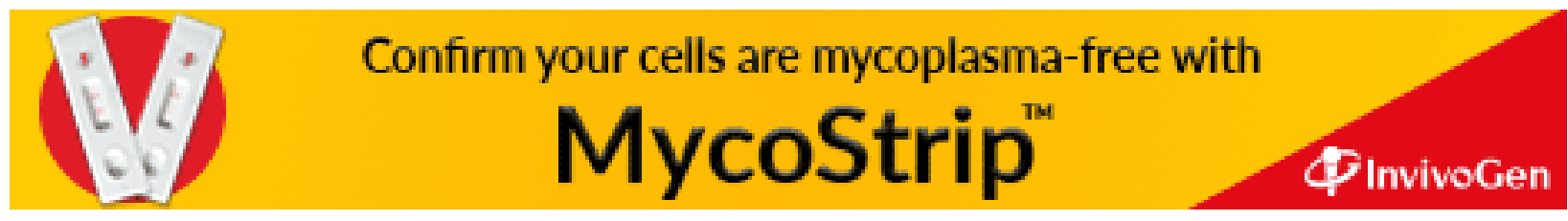

